\title{
Gobernando sin mayorías parlamentarias en América Latina'
}

\author{
Margarita Jiménez Badillo \\ Instituto Internacional de Estudios Políticos Avanzados, \\ Mexico
}

\begin{abstract}
Resumen: En América Latina es común que la institución presidencial se desempeñe con gobiernos sin mayorías parlamentarias, dificultándose la aprobación de la agenda de gobierno en el congreso. El objetivo de este estudio es exponer los componentes que determinan la posibilidad de articular consensos entre los poderes ejecutivo y legislativo en la arena parlamentaria. Se sostiene que a mayor distancia ideológica, menos posibilidades de integrar coaliciones para despejar la agenda política.
\end{abstract}

Palabras clave: ejecutivo-legislativo, legislaturas latinoamericanas, gobernabilidad, democracia

Abstract: In Latin America, presidential governments rule without parliamentary majority. The aim of this article is to show the determinants of consensus between the executive and legislative, and to affirm that the greater the ideological distances the lesser are the possibilities to make coalitions.

Key Words: executive-legislative, latinamerican parliaments, governability, democracy

\footnotetext{
1 Una versión preliminar de este estudio fue presentado en el 3o. Congresso Latinoamericano de Ciência Política: Democracia e Desigualdades. Universidade Estadual de Campinas, 4 a 6 de Setembro de 2006 y fue desarrollado en el marco del Proyecto "Los congresos Estatales mexicanos y la experiencia legislativa autonómica española: campos fecundos para la cooperación política” financiado por el Centro de Estudios para América Latina y la Cooperación Internacional (CeALCI 12/05) de la Fundación Carolina, España 2005-2006 y coordinado por Ernesto Hernández Norzagaray, Universidad Autónoma de Sinaloa; Igor Vivero Ávila Universidad Autónoma del Estado de México y Margarita Jiménez Badillo Universidad Autónoma de Guerrero.
} 
BADILLO, M. J. Gobernando sin mayorias parlamentarias en América Latina....

“El funcionamiento de todos los regímenes políticos es eficazmente explicable sólo en la medida en que se explican las relaciones entre gobierno y oposición"

(PASQUINO, G. 1990/1997, p. 42)

\section{Presentación}

Un factor relevante en América Latina en estos primeros años del siglo XXI es el nivel de satisfacción que se tiene respecto al funcionamiento de la democracia. No obstante el avance democrático en América Latina, la ciudadanía sigue demandando un rendimiento de las instituciones para elevar su calidad de vida. En este amplio espectro en el que se incluyen aspectos políticos, económicos y sociales, se hace necesario reflexionar acerca de qué tan eficaces son las instituciones políticas no sólo en mantener la gobernabilidad democrática sino para tomar decisiones orientadas a aumentar la calidad de la democracia.

Un debate central en esta línea es cómo garantizar la gobernabilidad en América Latina, la cual, en su mayoría, experimenta como parte de su normalidad cotidiana una división de poderes con gobiernos sin mayorías. Existe gobierno sin mayorías parlamentarias cuando el partido o coalición del presidente no tiene el control mayoritario de escaños en el congreso, y, ante una presencia significativa de fuerzas de oposición, el conflicto deviene de tener los dos bloques, intereses distintos, por lo que se pone en riesgo las decisiones eficientes para determinar las políticas de gobierno. Teóricamente, el umbral de escaños para hablar de un gobierno con mayoría absoluta o gobierno unificado es cuando el partido del presidente alcanza el 50 por ciento más uno de los escaños en el congreso.

La relación entre los poderes ejecutivo y legislativo con oposición mayoritaria es un punto de atención que ha devenido en argumentaciones de crisis políticas, bloqueo institucional y hasta ingobernabilidad. Contrariando esta línea de análisis, se muestra aquí, mediante algunos componentes institucionales e ideológicos, que esta variable no es determinante para generar distorsión en el funcionamiento de las instituciones políticas. El desempeño de los presidentes con contingentes legislativos minoritarios alienta más bien, el contrapeso de poderes, así como un papel reivindicador de los congresos, que tradicionalmente se les han considerado como subordinados a las decisiones de la figura presidencial.

Factores de diseño institucional, reformas políticas y de carácter electoral han propiciado que el poder legislativo opere con mayorías divididas. Cuando el presidente controla la mayoría absoluta en el congreso, su capacidad para ver aprobados los proyectos de ley ordinarios y reformas constitucionales que propone será mucho más flexible. Sin embargo, contar con gobierno unificado puede limitar ampliamente el contrapeso de poderes. 
El objetivo de este estudio es exponer los componentes que determinan la posibilidad de articular consensos entre los partidos en la arena parlamentaria. Esto es, qué elementos favorecen o limitan la capacidad de los presidentes para despejar su agenda política en un contexto de minoría parlamentaria. Asimismo, se avanzan elementos que permiten distinguir la estructuración ideológica de los sistemas de partidos en la región latinoamericana.

Los datos aportados representan una diversidad del comportamiento institucional que difícilmente puede llevar a generalizaciones teóricas y/o empíricas. Se asume más bien el precepto de que dicha diversidad es apenas un recorrido exploratorio que ofrece pautas para interpretar los procesos políticos contemporáneos en América Latina, coincidiendo así con la tesis de tener en cuenta la peculiaridad de cada caso nacional y el respeto a sus tradiciones, culturas y estructuras políticas (NOHLEN, 1998, p. 25) y dejando abierta la posibilidad de estudios de caso y comparados para avanzar en el conocimiento de cómo funcionan las instituciones políticas (TSEBELIS, 2002/2006).

En el primer apartado de este estudio, se identifica la imagen que tienen las instituciones políticas (presidente, parlamento y partidos) desde la valoración de la opinión pública, así como de los propios legisladores, un componente relevante para entender el comportamiento de las elites y su compromiso con la democracia. Después se exponen brevemente los poderes constitucionales y legislativos del presidente, factores que inciden en la posibilidad de despejar la agenda presidencial. En otro apartado, se avanza en definir la estructuración ideológica de los sistemas de partidos en América Latina, considerando que la ideología determina los nichos de competencia entre los partidos, por lo que es un componente indispensable en la argumentación de la capacidad presidencial para hacer aprobar su agenda de gobierno. Más adelante, se muestra que la agenda presidencial ha tenido un grado elevado de éxito sea en gobiernos unificados o de mayorías divididas. Por último, se aportan algunas reflexiones finales.

\section{Valoración del desempeño de las instituciones políticas}

La división de poderes en el presidencialismo latinoamericano ha provocado un amplio debate que resalta problemas de gobernabilidad por los conflictos en el desempeño institucional entre el ejecutivo y el legislativo. Reiterados argumentos acentúan la tesis de que en un escenario de mayorías divididas se dificulta la formulación de las políticas públicas, ya que las fuerzas representadas en el 
congreso tienen un potencial poder de veto capaz de impedir la aprobación de las iniciativas presidenciales².

En la literatura académica se han identificado dos generaciones de debate sobre las dificultades para gobernar en el presidencialismo latinoamericano. MAINWARING (2004) ubica la primera cuando inician las transiciones a la democracia. Una vez superada esta fase, la segunda, a decir del autor de referencia, se da hoy cuando se centra la atención en cómo construir democracias que funcionen. En el trasfondo de estos debates está claro que América Latina apostó y sigue apostando por la democracia. Sumando ya un cuarto de siglo su durabilidad, aunque se trate de una democracia de mínimos (ZOVATTO y BURDMAN, 2005), el reto ahora es construir una democracia de calidad y sostenible en el tiempo ${ }^{3}$.

Efectivamente, luego de las transiciones democráticas de los sistemas políticos latinoamericanos, desde mediados de los años setenta, al ser desplazados los regímenes militares en el gobierno, los partidos políticos fueron recobrando su identidad como vías fundamentales de articulación política con la sociedad. Un contexto en el que los valores democráticos empezaron a dominar la arena política y en el que los distintos actores apostaron por "la democracia como preferible a cualquier otra forma de gobierno", como lo indica el seguimiento que ha venido haciendo por más de una década, la Corporación Latinobarómetro en Chile, de la opinión pública en 18 países de América Latina4.

Diluidas hoy las amenazas de reemplazar a la democracia por el autoritarismo ${ }^{5}$, han surgido nuevos desafíos que apuntan a consolidar los procesos

\footnotetext{
2 Uno de los principales teóricos que ha suscitado gran controversia a favor, o contraviniendo estas tesis, ha sido Juan Linz, al sostener que las características propias del presidencialismo latinoamericano no puede favorecer la democracia y en cambio existen más bondades del sistema parlamentario. Ver LINZ (1997, p. 25-143); LINZ (1996) e LINZ, J. (1990). Las tesis que sostiene Linz son relativas a la rigidez del presidencialismo, ausencia de un poder legislativo autónomo, doble legitimidad (presidente y congreso), que el sistema parlamentario garantiza más la durabilidad de la democracia que el presidencialismo. Un presidencialismo con sistema multipartidista ha sido igualmente puesto a debate porque dificulta las relaciones de cooperación entre los poderes ejecutivo y legislativo (MAINWARING, 1995).

3 La calidad de la democracia es una noción muy amplia que está orientada a encontrar mecanismos para lograr la eficacia de las instituciones políticas para superar los niveles de vida y bienestar social de la población. O’DONNELL (1999) agrega un argumento moral y político considerando que la democracia se funda en valores que exigen una actitud respetuosa hacia la dignidad y autonomía de cada ser humano y, por muy imperfecta que sea la democracia, sigue siendo la forma de gobierno que ofrece mayores posibilidades que cualquier otra forma política.

4 El Informe 1996-2006 del Latinobarómetro al preguntar a la ciudadanía de los 18 países de América Latina si "la democracia es preferible a cualquier otra forma de gobierno" reportó estar de acuerdo en una media del 58 por ciento frente al 53 por ciento obtenido en 2005 . Estos datos indican que existe un apoyo a la democracia cada vez superior si se compara con el año 2001 cuando registró un 48 por ciento. Una población más escéptica es la que le da lo mismo un gobierno democrático o autoritario (media de 17 por ciento en 2006).

${ }^{5}$ El estudio realizado igualmente por el Latinobarómetro para 2005 al pulsar la opinión ciudadana con la pregunta: ¿apoyaría usted un gobierno militar en reemplazo del gobierno democrático, si las cosas se ponen muy difíciles, o no apoyaría usted en ninguna circunstancia a un gobierno militar? El país de más alto grado de rechazo a apoyar un gobierno militar fue Costa Rica (94 por ciento) seguido de Panamá y Uruguay (77 y
} 
democráticos con acciones políticas para elevar la calidad de vida de las sociedades. Es en este marco que cobra importancia el desempeño institucional y el rol que juegan los partidos políticos, el parlamento y la presidencia en la calidad de la democracia, en espera de superar las falacias en el quehacer político donde prevalecen estructuras clientelares y poderes personalistas que impiden una eficaz coordinación interinstitucional evidenciada en la percepción de los ciudadanos respecto al funcionamiento de dichas instituciones políticas.

Intentando indagar con qué credibilidad cuentan las instituciones políticas en su desempeño se han consultado los resultados de las encuestas de: 1) La opinión ciudadana, obtenida del Latinobarómetro y 2) La opinión de los legisladores de cada congreso en Latinoamérica ${ }^{6}$, esto es, la valoración de sí mismos como representantes de la voz ciudadana.

1) Opinión ciudadana. Al hacer un balance de 18 países durante una década en la confianza ciudadana en las instituciones políticas (1996-2006) ${ }^{7}$, el promedio que obtuvo la presidencia en América Latina muestra una tendencia ascendente de confianza del 39 por ciento en 1997 al 47 por ciento en 2006, lo cual indica que la figura presidencial viene recuperando una imagen en su gestión, aunque no alcanza a convencer ni a la mitad de la población (Gráfico 1).

76 por ciento, respectivamente). En contraparte, los países que más anuencia reconocieron fueron Perú y Honduras, ambos con el 48 por ciento, además de Paraguay con el 31 por ciento. México respondió en un 63 por ciento que en ninguna circunstancia apoyaría un gobierno militar. El promedio de América Latina en esta respuesta fue del 62 por ciento.

${ }^{6}$ Para este fin se consultaron los Boletines del Instituto Interuniversitario de Estudios de Iberoamérica de la Universidad de Salamanca, publicados en el marco del Proyecto Elites Parlamentarias Latinoamericanas coordinado por Manuel Alcántara Sáez y financiado por el Plan Nacional de Ciencia y Tecnología, España. 7 La pregunta que dicha Corporación ha aplicado a la población Latinoamérica es: Diría usted que tiene mucha, algo, poca o ninguna confianza en...el presidente, el congreso, etc. Los promedios concentran las respuestas de mucha y de algo de confianza. 
Gráfico 1 - Grado de confianza social en las instituciones (en porcentajes)

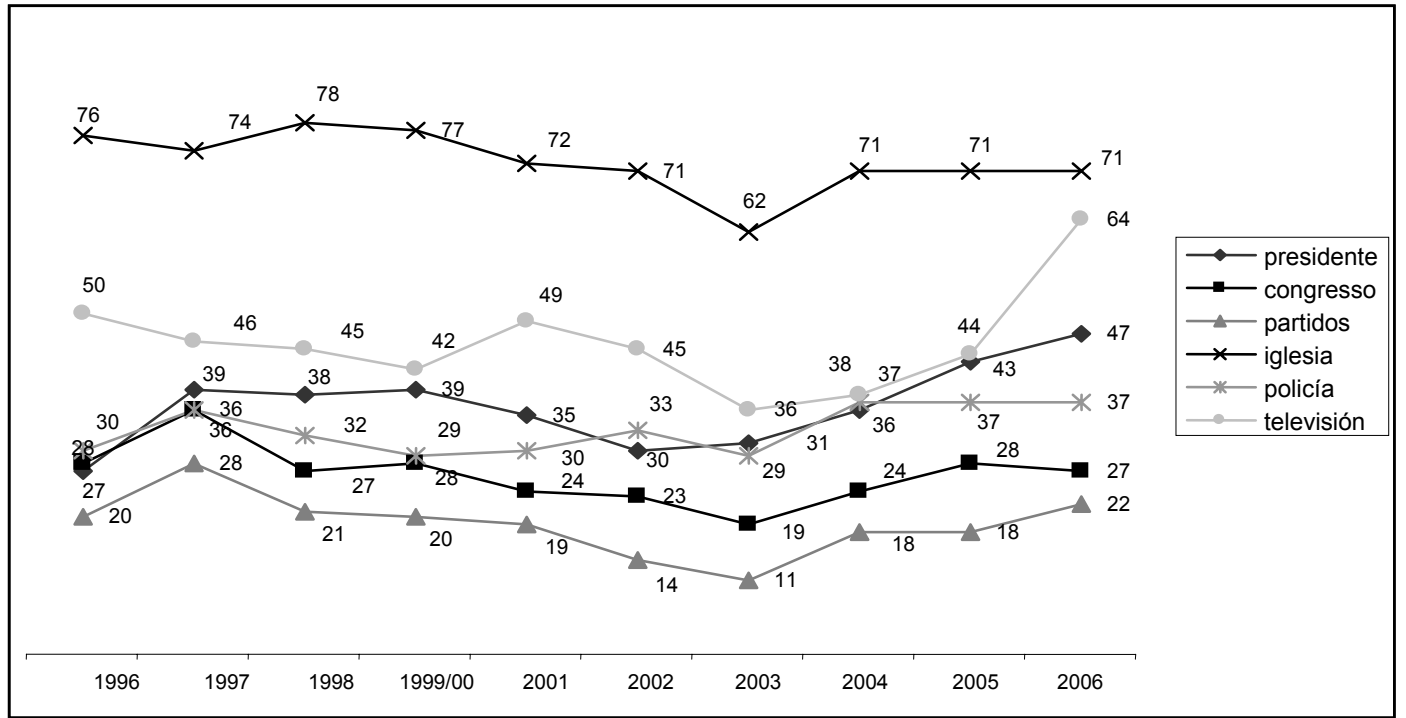

Fonte: Latinobarometro (1996-2006)

Más bajo nivel de confianza tiene el congreso que prácticamente en una década tiene la escasa confianza del 27 por ciento, así como los partidos, que, de las tres instituciones, son los que menos confianza le representan a la sociedad. La desconfianza en dichas instituciones políticas puede tener su explicación en la forma de hacer política, donde sus actores políticos no han podido apartarse de prácticas de corrupción y mal manejo de los recursos nacionales ${ }^{8}$. El ejercicio del poder de la figura presidencial ha devenido en la práctica, en una amplia concentración del poder político, obstaculizado el ejercicio de las responsabilidades delegadas a mandos intermedios.

No obstante, lo alarmante que resultan estas cifras, lo cierto es que las tres instituciones han funcionado en el marco de una débil democracia en unos países y más consolidada en otros, alejando las amenazas de regímenes autoritarios en la región y tanto militares como civiles han asumido en términos de PRZEWORSKI (1996) el acatamiento de las reglas del juego de la democracia. Aún cuando los partidos políticos son los peor evaluados son necesarios porque:

\footnotetext{
8 Una explicación del Latinobarómetro al bajo nivel de confianza en los partidos y el parlamento es que se trata de actores "invisibles", esto es, que no son cercanos a la ciudadanía, al no existir interacción de vida de los ciudadanos con estas instituciones. Se trata de un argumento dentro de lo que dicha Corporación ha definido como democracia experiencial, esto es, que los latinoamericanos aprecian las cosas no conceptualmente sino en la medida que las pueden experimentar (Ver Informe Latinobarómetro, 2006, p. 31).
} 
“...continúan realizando funciones centrales en los sistemas políticos, aunque desempeñen mal las de representación y articulación de demandas; también siguen participando y estructurando la competencia política; seleccionando a los representantes; contribuyendo a la socialización de los ciudadanos, aunque cada vez en menor medida; dirigiendo el gobierno y la administración pública; estableciendo la agenda pública y coadyuvando en el establecimiento de la agenda mediática; actuando como oposición, incluso, realizando tareas de fiscalización y, en fin, haciendo operativo el sistema político" (ALCÁNTARA, 2006, p. 10).

Así pues, son tres instituciones que deben funcionar reproduciendo las pautas necesarias para vigorizar la democracia en la región. A efectos de comparación, se incluyen otras instituciones en el mismo Gráfico 1, como son la policía, la televisión y la iglesia. Se observa claramente que la imagen de la policía siempre ha sido superior a la que guardan los partidos, no obstante que también representa a la sociedad una baja confianza como lo reportan los datos en 2006, que fue del 37 por ciento. La televisión tiene mayor aceptación (64 por ciento) y ambas son superadas por la iglesia, que tiene un nivel de confianza ciudadana del 71 por ciento. Probablemente, la valoración tiende a hacerse en función de los valores creados y reproducidos en su cotidianidad inmediata y, en efecto, los partidos o el congreso resulten ser "imperceptibles" porque hace falta un acercamiento mayor con la sociedad.

2) Opinión de los legisladores. La confianza que les ha representado la institución presidencial, el mismo congreso y los partidos, según datos del equipo de Elites Parlamentarias de la Universidad de Salamanca (Tabla 1), es más alta para la valoración del congreso en las dos etapas de estudio. La media total para América Latina comparando dos períodos legislativos es del 71,7 y 72,3, respectivamente; es decir, los miembros del congreso lo evalúan con mayor confianza puesto que ellos son quienes hacen que funcione. Con respecto a las otras instituciones, el presidente tiene un porcentaje de confianza mayor que el que otorgan a los partidos. Es significativo porque entonces tanto elites como ciudadanos coinciden en valorar con mínima confianza a los partidos, un punto de alerta más aún cuando los legisladores que son miembros de algún partido reconocen que dichos institutos tienen una débil institucionalización y volatilidad que conlleva a una crisis de los sistemas de partidos. 


\begin{tabular}{|c|c|c|c|c|c|c|c|c|}
\hline \multicolumn{9}{|c|}{$\begin{array}{l}\text { Tabla 1. Grado de confianza que otorgan las elites parlamentarias a las instituciones } \\
\text { políticas de su país (valores de mucho y bastante en porcentajes) }\end{array}$} \\
\hline & \multicolumn{5}{|c|}{ Primera Ełapa* } & \multicolumn{3}{|c|}{ Segunda Etapa } \\
\hline País & Legislatura & Presidente & $\begin{array}{c}\text { parlament } \\
0\end{array}$ & Partidos & Legislatura & presidente & parlamento & Partidos \\
\hline Argentina & $\begin{array}{l}1997 . \\
2001\end{array}$ & 46,9 & 65,6 & 59,8 & 2003-2007 & 76,7 & 66,5 & 36,3 \\
\hline Bolivia & $\begin{array}{l}1997 . \\
2002\end{array}$ & 65,3 & 54,1 & 32,7 & $2002 \cdot 2007$ & 37,2 & 40,3 & 25,9 \\
\hline Brasil & . & . & . & . & $2003 \cdot 2007$ & 67,9 & 76,9 & 51,5 \\
\hline Chile & $\begin{array}{l}1997 . \\
2001\end{array}$ & 91,0 & 84,1 & 56,2 & $2001 \cdot 2005$ & 96,6 & 81,5 & 55,3 \\
\hline Colombia & $\begin{array}{l}1998 \\
2002\end{array}$ & 87,3 & 66,3 & 45,5 & $2002 \cdot 2006$ & 87,9 & 63,6 & 24,1 \\
\hline Costa Rica & $\begin{array}{l}1998 \\
2002\end{array}$ & 85,8 & 79,6 & 67,3 & $2002 \cdot 2006$ & 76,5 & 72,5 & 33,4 \\
\hline Ecuador & $\begin{array}{l}1998 \\
2002\end{array}$ & 69,7 & 75,0 & 34,0 & $2002 \cdot 2006$ & 29,6 & 62,2 & 20,4 \\
\hline El Salvador & $\begin{array}{l}2000 \\
2003\end{array}$ & 60,6 & 53,4 & 42,6 & 2003-2006 & 47,6 & 60,1 & 46,3 \\
\hline Honduras & $\begin{array}{l}1997 . \\
2001\end{array}$ & 80,3 & 81,7 & 64,8 & $2001 \cdot 2005$ & 74,9 & 82,0 & 59,4 \\
\hline Guatemala & $\begin{array}{l}2000 \\
2004\end{array}$ & 39,3 & 63,3 & 38,0 & $2004 \cdot 2008$ & 59,4 & 62,2 & 29,7 \\
\hline México & $\begin{array}{l}2000 \\
2003\end{array}$ & 61,0 & 89,4 & 58,5 & $2003 \cdot 2006$ & 64,0 & 72,2 & 65,8 \\
\hline Nicaragua & $\begin{array}{l}1997 . \\
2001\end{array}$ & 42,8 & 50,0 & 32,9 & $2002 \cdot 2006$ & 34,4 & 64,4 & 58,9 \\
\hline Panamá & $\begin{array}{l}1999 . \\
2004\end{array}$ & 60,9 & 59,4 & 51,6 & 2004-2009 & 82,4 & 88,2 & 73,5 \\
\hline Paraguay & $\begin{array}{l}1998 \\
2003\end{array}$ & 54,7 & 83,1 & 66,2 & 2003-2008 & 82.3 & 87,9 & 55,1 \\
\hline Perú & . & . & . & . & $2001 \cdot 2006$ & 83,2 & 74,3 & 40,5 \\
\hline $\begin{array}{c}\text { Rep. } \\
\text { Dominicana }\end{array}$ & $\begin{array}{l}1998 \\
2002\end{array}$ & 69,9 & 81,4 & 74,7 & $2002 \cdot 2006$ & 56,9 & 76,3 & 70,2 \\
\hline Uruguay & $\begin{array}{l}2000 \\
2005\end{array}$ & 84,9 & 89,8 & 88,5 & $2005 \cdot 2010$ & 87,8 & 96,5 & 93,2 \\
\hline Venezuela & . & . & . & . & $2000 \cdot 2005$ & 63,7 & 74,7 & 18,3 \\
\hline Medias & & 66,7 & 71,7 & 54,2 & & 62,5 & 72,3 & 47,6 \\
\hline \multicolumn{9}{|c|}{$\begin{array}{l}\text { Pregunta: En relación con a las siguientes instituciones, ¿qué grado de confianza mucha, bastante, poca o ninguna le merece } \\
\text { la actuación en la vida pública de su país? presidente, parlamento y Partidos.* En la primera etapa, por falta de datos se } \\
\text { omiten Brasil, Perú y Venezuela. }\end{array}$} \\
\hline $\begin{array}{l}\text { Fuente: Elat } \\
\text { Interunivers }\end{array}$ & $\begin{array}{l}\text { ración propia } \\
\text { ario de Estud }\end{array}$ & $\begin{array}{l}\text { con datos de } \\
\text { bs de Iberoan }\end{array}$ & $\begin{array}{l}\text { Boletines de } 0 \\
\text { érica. Univers }\end{array}$ & $\begin{array}{l}\text { inión Elites } \\
\text { ad de Sal }\end{array}$ & $\begin{array}{l}\text { arlamentarias } L \\
\text { lanca. }\end{array}$ & tinoamerican & para cada país & nstituto \\
\hline
\end{tabular}

Se observa en la Tabla 1 también que Chile es la nación que mayor confiabilidad le ha representado su presidente a los legisladores (91 por ciento en 1997-2001 y 96,6 por ciento en 2001-2005), lo cual va acorde con la satisfacción que pueda reportar la relación entre los poderes ejecutivo y legislativo en una democracia consolidada y en contraparte, países como Nicaragua, Guatemala, Ecuador y el Salvador tienden a manifestar mayor tensión en sus instituciones políticas. 
Dada la limitada credibilidad de estas instituciones políticas que tienen una cierta parcela de poder, de su grado de articulación depende en gran parte su rendimiento para favorecer la calidad de la democracia. "La cooperación interinstitucional puede producir resultados poco satisfactorios si no se basa en una amplia representación de las diversas tendencias políticas que cuenten con apoyo de los ciudadanos" (COLOMER, 2003).

Esta cooperación depende también de la naturaleza de los poderes ejecutivo y legislativo por cuanto a sus facultades constitucionales y legislativas que regulan su capacidad para coaligar y despejar los proyectos de ley presidenciales. Si el planteamiento inicial ha sido sostener que los gobiernos sin mayorías no son determinantes para una parálisis institucional, bien puede entonces abonarse argumentos que expliquen por qué se ha mantenido el funcionamiento de los poderes ejecutivo y legislativo en este formato sin mayorías parlamentarias.

Poderes constitucionales y partidarios del presidente.

Cuando el presidente no tiene mayorías en el congreso tiene que buscar otros mecanismos para llevar a cabo su programa de gobierno. La capacidad del presidente en el proceso legislativo está estrechamente relacionada con la interacción entre sus poderes constitucionales (veto y decreto) que le otorgan flexibilidad para ejercer poder en la agenda política ${ }^{9}$ aún sin contar con una mayoría legislativa y los poderes partidarios, que son las facultades presidenciales para definir el proceso de elaboración de las leyes, así como del control que tiene sobre su partido o partidos y del número de los escaños que éstos ostenten (SHUGART y MAINWARING, 1997/2002, p. 20).

Las competencias legislativas del presidente se identifican como poderes reactivos, que son los que le permiten defender el statu quo contra las tentativas de la mayoría legislativa (poder de veto). Los poderes proactivos son los poderes que permiten al presidente tomar decisiones para establecer, o tratar de establecer, un nuevo statu quo (decreto) (SHUGART y MAINWARING, 1997/2002, p. 50).

Los legisladores, en su calidad de actores relevantes, tienen poder de veto para mantener el statu quo o producir el cambio en las políticas de la agenda de gobierno. Tal recurso de poder político es el que frena o favorece las condiciones para evitar el conflicto entre los poderes ejecutivo y legislativo. Aquí intervienen variables como la heterogeneidad de los intereses de los legisladores y sus grupos

\footnotetext{
${ }^{9}$ El poder de agenda de un presidente es la capacidad que tiene para determinar qué iniciativas de ley someterá al congreso y cuándo lo hará. Un mayor poder de agenda es la capacidad del ejecutivo para influir directamente en el trabajo legislativo (LIMONGI Y FIGUEIREDO, 1988, p. 86, citados en NOLTE, 2003, p. 50).
} 
parlamentarios, así como las prioridades que cada cual pretende impulsar, y, en todo caso, los consensos para facilitar la cooperación (SHEPSLE y BONCHEK, 2004/2005, p. 301-310).

El presidente mexicano cuenta con poderes reactivos, es decir, que sólo tiene poder de veto y no de decreto y no puede fijar de manera exclusiva la elaboración de las políticas; el congreso, según su composición, puede influir en la agenda conjuntamente con el ejecutivo. De estas variaciones institucionales depende el rendimiento de los actores políticos en la elaboración de las políticas.

Ahora bien, ¿cómo definir si el presidente ve aprobada su agenda política y con qué grado se da ésta?, ¿cómo definir si el presidente es fuerte o débil? En la literatura politológica se ha sostenido que un presidente es fuerte cuando define las políticas, y por tanto tiene capacidad para llevar a cabo su agenda; por el contrario, los presidentes débiles son cuando sus asambleas son las que definen la agenda, no tienen autoridad constitucional independiente sobre la legislación; y son muy débiles si carecen del control de un partido mayoritario. Así, determinar cuánto poder tiene el presidente en términos constitucionales, está en razón de sus facultades legislativas y en particular de su poder de veto. presidentes con poder de veto "fuerte" pueden ratificar o vetar la legislación y presidentes con poderes de decreto pueden incluso legislar sin la participación del congreso (SHUGART y CAREY, 1992) como ha sido en Argentina y Brasil.

Los presidentes fuertes lo son por el marco constitucional en el que se desempeñan y, al canalizar las iniciativas para el congreso, éste tiene en cuenta las preferencias del presidente a la hora de ser dictaminadas. Asimismo, se tratará de un presidente fuerte cuando tenga el control de su partido y más aún si éste tiene la mayoría de escaños en el congreso (poderes partidarios). Así, un presidente tiende a ser más fuerte o débil dependiendo de la posición que tenga frente al sistema de partidos y de sus facultades en materia legislativa.

Si los sistemas de partidos son más institucionalizados ${ }^{10}$ es más factible la conformación de coaliciones legislativas que definan la agenda política. En cambio, en sistemas de partidos de débil institucionalización como es el caso ecuatoriano existe mayor indisciplina de sus miembros, y menos cohesión interna para forjar coaliciones más duraderas. El presidente en estas circunstancias tiende a buscar incentivos hasta recurriendo a miembros clave de las legislaturas para buscar consensos y lograr el respaldo del congreso en sus iniciativas.

\footnotetext{
10 Un sistema de partidos es institucionalizado cuando: 1) Hay competencia regular entre partidos; 2) Los partidos tienen raíces estables en la sociedad 3) Los partidos y las elecciones son los mecanismos para determinar quién gobierna y 4) Las organizaciones partidarias deben ser relativamente sólidas (MAINWARING y SCULLY, 1997).
} 


\section{Gobernando en congresos de mayorías divididas}

En el presidencialismo latinoamericano existe una normativa muy variada en los mecanismos de selección y permanencia en el cargo del ejecutivo y el legislativo. De estos criterios depende en parte la capacidad de ambos poderes para despejar la agenda política. La Tabla 2 muestra que la mitad de 18 países en la región tiene una estructura unicameral del Poder legislativo, con la posibilidad de reelección de sus miembros a excepción de Costa Rica ${ }^{11}$. Al igual que la restricción en el período del mandato presidencial en este país, se explica para evitar la perpetuación en el poder del partido gobernante. Igualmente la oposición impuso el mismo criterio en la asamblea; en México la no reelección procede de la clase política que, al negar la reelección, sujetaba a las elites a guardar lealtades si querían continuar su carrera política. Sólo seis países impiden la reelección presidencial, mientras que otros lo permiten consecutivamente o bien después de un período presidencial.

\begin{tabular}{|c|c|c|c|c|c|c|c|}
\hline & nstitución & oresidencial & & & Po & $r$ legislativo & \\
\hline País & $\begin{array}{l}\text { Tipo de } \\
\text { sistema }\end{array}$ & $\begin{array}{l}\text { Período } \\
\text { presiden } \\
\text { cial }\end{array}$ & $\begin{array}{c}\text { Reelección } \\
\text { Presiden } \\
\text { cial }\end{array}$ & congreso & Escaños & $\begin{array}{c}\text { Período } \\
\text { legislativo }\end{array}$ & $\begin{array}{l}\text { Reelección } \\
\text { Legislativa }\end{array}$ \\
\hline Argentina & Federal & 4 & Inmediata & $\begin{array}{l}\text { Diputados } \\
\text { senadores }\end{array}$ & $\begin{array}{c}257 \\
72\end{array}$ & $\begin{array}{l}4 \\
6\end{array}$ & $\begin{array}{l}\text { Indefinida* } \\
\text { Indefinida }\end{array}$ \\
\hline Bolivia & Unitario & 4 & $\begin{array}{c}\text { No } \\
\text { inmediata }\end{array}$ & $\begin{array}{l}\text { Diputados } \\
\text { senadores }\end{array}$ & $\begin{array}{c}130 \\
54\end{array}$ & $\begin{array}{l}5 \\
5\end{array}$ & $\begin{array}{l}\text { Indefinida } \\
\text { Indefinida }\end{array}$ \\
\hline Brasil & Federal & 4 & Inmediata & $\begin{array}{l}\text { Diputados } \\
\text { senadores }\end{array}$ & $\begin{array}{l}513 \\
81\end{array}$ & $\begin{array}{l}4 \\
8\end{array}$ & $\begin{array}{l}\text { Indefinida } \\
\text { Indefinida }\end{array}$ \\
\hline Chile & Unitario & 6 & $\begin{array}{c}\text { No } \\
\text { inmediata }\end{array}$ & $\begin{array}{l}\text { Diputados } \\
\text { senadores }\end{array}$ & $\begin{array}{c}120 \\
38\end{array}$ & $\begin{array}{l}4 \\
8\end{array}$ & $\begin{array}{l}\text { Indefinida } \\
\text { Indefinida }\end{array}$ \\
\hline Colombia & Unitario & 4 & No & $\begin{array}{l}\text { Diputados } \\
\text { senadores }\end{array}$ & $\begin{array}{c}166 \\
83\end{array}$ & $\begin{array}{l}4 \\
4\end{array}$ & $\begin{array}{l}\text { Indefinida } \\
\text { Indefinida }\end{array}$ \\
\hline Costa Rica & Unitario & 4 & No & Unicameral & 57 & 4 & No consecutiva \\
\hline Ecuador & Unitario & 4 & $\begin{array}{c}\text { No } \\
\text { inmediata }\end{array}$ & Unicameral & 100 & 4 & Indefinida \\
\hline El Salvador & Unitario & 5 & $\begin{array}{c}\text { No } \\
\text { inmediata }\end{array}$ & Unicameral & 84 & 3 & Indefinida \\
\hline Guatemala & Unitario & 4 & No & Unicameral & 158 & 4 & Indefinida \\
\hline Honduras & Unitario & 4 & No & Unicameral & 128 & 4 & Indefinida \\
\hline México & Federal & 6 & No & $\begin{array}{l}\text { Diputados } \\
\text { senadores }\end{array}$ & $\begin{array}{l}500 \\
128\end{array}$ & $\begin{array}{l}3 \\
6\end{array}$ & $\begin{array}{l}\text { No consecutiva } \\
\text { No consecutiva }\end{array}$ \\
\hline Nicaragua & Unitario & 5 & $\begin{array}{c}\text { No } \\
\text { inmediata }\end{array}$ & Unicameral & 92 & 5 & Indefinida \\
\hline Panamá & Unitario & 5 & $\begin{array}{c}\text { No } \\
\text { inmediata }\end{array}$ & Unicameral & 78 & 5 & Indefinida \\
\hline Paraguay & Unitario & 5 & No & $\begin{array}{l}\text { Diputados } \\
\text { senadores }\end{array}$ & $\begin{array}{l}80 \\
45 \\
\end{array}$ & $\begin{array}{l}5 \\
5\end{array}$ & $\begin{array}{l}\text { Indefinida } \\
\text { Indefinida }\end{array}$ \\
\hline
\end{tabular}

${ }^{11}$ Un estudio de Costa Rica, así como Venezuela en su mayor extensión respecto al tema de la reelección lo presenta CAREY (1996/2006). 
BADILLO, M. J. Gobernando sin mayorias parlamentarias en América Latina....

\begin{tabular}{|c|c|c|c|c|c|c|c|}
\hline País & $\begin{array}{l}\text { Tipo de } \\
\text { sistema }\end{array}$ & $\begin{array}{l}\text { Período } \\
\text { presiden } \\
\text { cial }\end{array}$ & $\begin{array}{c}\text { Reelección } \\
\text { Presiden } \\
\text { cial }\end{array}$ & congreso & Escaños & $\begin{array}{c}\text { Período } \\
\text { legislativo }\end{array}$ & $\begin{array}{l}\text { Reelección } \\
\text { Legislativa }\end{array}$ \\
\hline Perú & Unitario & 5 & Inmediata & Unicameral & 120 & 5 & Indefinida \\
\hline \multirow{2}{*}{$\begin{array}{c}\text { República } \\
\text { Dominican } \\
\text { a }\end{array}$} & \multirow[b]{2}{*}{ Unitario } & \multirow[b]{2}{*}{4} & \multirow{2}{*}{$\begin{array}{c}\text { No } \\
\text { inmediata }\end{array}$} & Diputados & 178 & 5 & Indefinida \\
\hline & & & & senadores & 32 & 4 & Indefinida \\
\hline Uruguay & Unitario & 5 & $\begin{array}{c}\text { No } \\
\text { inmediata }\end{array}$ & $\begin{array}{l}\text { Diputados } \\
\text { senadores }\end{array}$ & $\begin{array}{l}99 \\
31\end{array}$ & $\begin{array}{l}5 \\
5\end{array}$ & $\begin{array}{l}\text { Indefinida } \\
\text { Indefinida }\end{array}$ \\
\hline Venezuela & Federal & 6 & Inmediata & Unicameral & 167 & 5 & $1+2$ períodos \\
\hline
\end{tabular}

* Renovación de la mitad de sus miembros cada dos años.

Fuente: Elaboración propia

Un aspecto clave del funcionamiento de los regímenes presidencialistas es el apoyo que el presidente tiene del congreso. En América Latina, es una práctica común que el partido al que pertenece el presidente no tenga el control de la asamblea parlamentaria. En México, se da desde 1997, y en ambas situaciones es imperativa la necesidad de alcanzar acuerdos para facilitar la conformación de coaliciones parlamentarias y despejar la agenda política. Por tanto, es a partir de este escenario que las relaciones institucionales entre los poderes ejecutivo y legislativo se modifican sustancialmente de cara a su desempeño legislativo en gobiernos de mayorías divididas.

Por ello, el principal rol de los partidos en este marco es desafiar a la elite gobernante participando en el proceso decisorio de la vida política, en virtud de que la buena gobernanza no implica la neutralización de las instituciones ni el dominio de la presidencia sino otorgarle un papel prioritario al congreso (COLOMER Y NEGRETTO, 2003).

Es así que los mecanismos para gobernar con estabilidad política están en razón de la capacidad de ambos poderes de lograr coaliciones partidarias y sancionar las iniciativas de ley que son parte de la agenda de gobierno.

La Tabla 3 resume el apoyo parlamentario con el que ha contado el presidente latinoamericano, traducido a número de escaños que le respalda. Obsérvese que en la mayoría de los países se han establecido las relaciones entre los poderes ejecutivo y legislativo con congresos de mayoría dividida, donde el partido o coalición del presidente no alcanzó un número de escaños superior al 50 por ciento más uno para contar con la mayoría absoluta y tener la capacidad de definir por sí mismo la agenda de gobierno. Por el contrario, se tiene una pluralidad de fuerzas políticas representadas en la arena parlamentaria, lo cual obliga tanto al ejecutivo como al legislativo a la negociación para generar consensos en la elaboración de las políticas, más aún cuando se trata de reformas constitucionales, que exigen un número mayor de legisladores a favor de una ley para producirse el cambio. 


\begin{tabular}{|c|c|c|c|c|c|c|c|c|}
\hline \multicolumn{9}{|c|}{$\begin{array}{l}\text { Tabla } 3 . \text { Gobiernos unificados y sin mayorías en América Latina } \\
\text { (escaños en número y porcentaje del partido o coalición de gobierno) }\end{array}$} \\
\hline \multirow[t]{2}{*}{ País } & \multirow{2}{*}{$\begin{array}{l}\text { Período } \\
\text { legislativo } \\
\text { o presidencial }\end{array}$} & \multirow[t]{2}{*}{ presidente } & \multirow{2}{*}{$\begin{array}{l}\text { Partido o coalición en el } \\
\text { gobierno }\end{array}$} & \multicolumn{2}{|c|}{$\begin{array}{l}\text { Cámara } \\
\text { baja }\end{array}$} & \multicolumn{2}{|c|}{$\begin{array}{l}\text { Cámara } \\
\text { alta }\end{array}$} & \multirow{2}{*}{$\begin{array}{l}\text { Tipo de } \\
\text { gobierno }\end{array}$} \\
\hline & & & & $\mathrm{N}$ & $\%$ & $\mathrm{~N}$ & $\%$ & \\
\hline Argentina & 1997.1999 & Carlos Menem & Partido Justicialista & 118 & 46,0 & 37 & 51,4 & SM \\
\hline Argentina & $1999 \cdot 2001$ & $\begin{array}{c}\text { Fernando de la } \\
\text { Rua }\end{array}$ & Alianza (UCR/FREPASO) & 124 & 48,2 & 20 & 27,7 & SM \\
\hline Argentina & $2001 \cdot 2003$ & $\begin{array}{l}\text { Rodríguez Saa, } \\
\text { Duhalde y otros }\end{array}$ & Partido Justicialista & 116 & 45,1 & 40 & 55,5 & SM \\
\hline Argentina & $2003 \cdot 2005$ & Nestor Kirchner & $\begin{array}{c}\text { PJ/Frente para la } \\
\text { Victoria }\end{array}$ & 129 & 51,0 & 41 & 56,9 & $U$ \\
\hline Argentina & $2005 \cdot 2007$ & Nestor Kirchner & $\begin{array}{c}\text { PJ/Frente para la } \\
\text { Victoria }\end{array}$ & 107 & 41,6 & 43 & 59,7 & SM \\
\hline Bolivia & $2006 \cdot 2007$ & Evo Morales & $\begin{array}{l}\text { Movimiento al } \\
\text { Socialismo }\end{array}$ & 72 & 55,3 & 12 & 44,4 & SM \\
\hline Brasil & 1999.2003 & $\begin{array}{c}\text { Fernando Enrique } \\
\text { Cardoso }\end{array}$ & $\begin{array}{c}\text { Partido Social } \\
\text { Democracia Brasileño }\end{array}$ & 95 & 18,5 & 16 & 19,6 & SM \\
\hline Brasil & $2003 \cdot 2007$ & $\begin{array}{l}\text { Inácio Lula da } \\
\text { Silva }\end{array}$ & $\begin{array}{l}\text { Partido de los } \\
\text { Trabajadores }\end{array}$ & 91 & 17,7 & 10 & 12,3 & SM \\
\hline Chile & $2000 \cdot 2006$ & Ricardo Lagos & $\begin{array}{l}\text { Concertación de } \\
\text { Partidos por la } \\
\text { Democracia }\end{array}$ & 62 & 47,9 & 20 & 51,3 & SM \\
\hline Chile & $2006 \cdot 2010$ & Michelle Bachelet & $\begin{array}{c}\text { Concertación por la } \\
\text { Democracia }\end{array}$ & 64 & 53,3 & 20 & 52,6 & U \\
\hline Colombia & $2006 \cdot 2010$ & Álvaro Uribe & Primero Colombia & 86 & 51,8 & 68 & 66,6 & $U$ \\
\hline Costa Rica & 1998.2002 & $\begin{array}{l}\text { Miguel Ángel } \\
\text { Rodríguez }\end{array}$ & $\begin{array}{c}\text { Partido Unidad Social } \\
\text { Cristiana }\end{array}$ & 27 & 47,4 & $\mathrm{n} / \mathrm{a}$ & $\mathrm{n} / \mathrm{a}$ & SM \\
\hline Costa Rica & $2002 \cdot 2006$ & Abel Pacheco & $\begin{array}{c}\text { Partido Unidad Social } \\
\text { Cristiana }\end{array}$ & 19 & 33,3 & $\mathrm{n} / \mathrm{a}$ & $\mathrm{n} / \mathrm{a}$ & SM \\
\hline Costa Rica & $2006 \cdot 2010$ & Oscar Arias & $\begin{array}{c}\text { Partido Liberación } \\
\text { Nacional }\end{array}$ & 25 & 43,9 & $\mathrm{n} / \mathrm{a}$ & $\mathrm{n} / \mathrm{a}$ & SM \\
\hline Ecuador & $1998 \cdot 2000$ & Jamil Mahuad & Democracia Popular & 35 & 28,0 & $\mathrm{n} / \mathrm{a}$ & $\mathrm{n} / \mathrm{a}$ & SM \\
\hline Ecuador & $2003 \cdot 2005$ & Lucio Gutiérrez & $\begin{array}{c}\text { Partido Sociedad } \\
\text { Patriótica } 21 \text { de Enero }\end{array}$ & 13 & 13,0 & $\mathrm{n} / \mathrm{a}$ & $\mathrm{n} / \mathrm{a}$ & SM \\
\hline Ecuador & $2005 \cdot 2007$ & Alfredo Palacios & Partido Social Cristiano & 24 & 22,2 & $\mathrm{n} / \mathrm{a}$ & $\mathrm{n} / \mathrm{a}$ & SM \\
\hline El Salvador & $1999 \cdot 2004$ & Francisco Flores & $\begin{array}{c}\text { Alianza Republicana } \\
\text { Nacionalista }\end{array}$ & 29 & 34,5 & $\mathrm{n} / \mathrm{a}$ & $\mathrm{n} / \mathrm{a}$ & SM \\
\hline El Salvador & 2004.2009 & $\begin{array}{l}\text { Elias Antonio } \\
\text { Saca González }\end{array}$ & $\begin{array}{c}\text { Alianza Republicana } \\
\text { Nacionalista }\end{array}$ & 27 & 32,1 & $\mathrm{n} / \mathrm{a}$ & $\mathrm{n} / \mathrm{a}$ & SM \\
\hline Guatemala & $2000 \cdot 2004$ & $\begin{array}{l}\text { Alfonso Portillo } \\
\text { Cabrera }\end{array}$ & $\begin{array}{l}\text { Frente Republicano } \\
\text { Guatemalteco FRG }\end{array}$ & 63 & 55,7 & $\mathrm{n} / \mathrm{a}$ & $\mathrm{n} / \mathrm{a}$ & $U$ \\
\hline Guatemala & $2004-2008$ & $\begin{array}{l}\text { Oscar Rafael } \\
\text { Berger }\end{array}$ & PP.MR-GANA & 39 & 30,7 & $\mathrm{n} / \mathrm{a}$ & $\mathrm{n} / \mathrm{a}$ & SM \\
\hline Honduras & $2002 \cdot 2006$ & $\begin{array}{c}\text { Ricardo Maduro } \\
\text { Joest }\end{array}$ & Partido Nacional & 61 & 47,6 & $\mathrm{n} / \mathrm{a}$ & $\mathrm{n} / \mathrm{a}$ & SM \\
\hline Honduras & $2006 \cdot 2010$ & $\begin{array}{l}\text { Manuel Zelaya } \\
\text { Rosales }\end{array}$ & $\begin{array}{l}\text { Partido Liberal } \\
\text { Hondureño }\end{array}$ & 53 & 41,1 & $\mathrm{n} / \mathrm{a}$ & $\mathrm{n} / \mathrm{a}$ & SM \\
\hline México & $2000 \cdot 2003$ & Vicente Fox & Partido Acción Nacional & 153 & 30,6 & 46 & 35,9 & SM \\
\hline México & 2003.2006 & Vicente Fox & Partido Acción Nacional & 207 & 41,4 & 47 & 36,7 & SM \\
\hline México & $2006 \cdot 2009$ & Felipe Calderón & Partido Acción Nacional & 205 & 41,0 & 52 & 40,6 & SM \\
\hline Nicaragua & $2002 \cdot 2007$ & Enrique Bolaños & $\begin{array}{l}\text { Partido Liberal } \\
\text { Constitucional }\end{array}$ & 52 & 57,7 & $\mathrm{n} / \mathrm{a}$ & $\mathrm{n} / \mathrm{a}$ & $U$ \\
\hline Nicaragua & $2007 \cdot 2012$ & Daniel Ortega & $\begin{array}{l}\text { Frente Sandinista de } \\
\text { Liberación Nacional }\end{array}$ & 38 & 41,3 & $\mathrm{n} / \mathrm{a}$ & $\mathrm{n} / \mathrm{a}$ & SM \\
\hline Panamá & $1999 \cdot 2004$ & Mireya Moscoso & Partido Arnulfista & 17 & 23,9 & $\mathrm{n} / \mathrm{a}$ & $\mathrm{n} / \mathrm{a}$ & SM \\
\hline Panamá & $2004 \cdot 2009$ & $\begin{array}{l}\text { Martín Torrijos } \\
\text { Espino }\end{array}$ & $\begin{array}{c}\text { Partido Revolucionario } \\
\text { Democrático }\end{array}$ & 41 & 52,5 & $\mathrm{n} / \mathrm{a}$ & $\mathrm{n} / \mathrm{a}$ & $U$ \\
\hline Paraguay & 1998.1999 & Raúl Cubas Grau & P Colorado/UNR & 45 & 52 & 24 & 49,3 & SM \\
\hline Paraguay & $1999 \cdot 2003$ & $\begin{array}{c}\text { Luis Ángel } \\
\text { González Machi }\end{array}$ & Partido Colorado** & 37 & 45,3 & 16 & 35,5 & SM \\
\hline
\end{tabular}


BADILLO, M. J. Gobernando sin mayorias parlamentarias en América Latina....

\begin{tabular}{|c|c|c|c|c|c|c|c|c|}
\hline Paraguay & $2003 \cdot 2008$ & Nicanor Duarte & $\begin{array}{c}\text { Asociación Nacional } \\
\text { Republicana Partido } \\
\text { Colorado ANR }\end{array}$ & 43 & 53,7 & 18 & 40 & SM \\
\hline Perú & $2001 \cdot 2006$ & Alejandro Toledo & Perú Posible & 35 & 29,2 & $\mathrm{n} / \mathrm{a}$ & $\mathrm{n} / \mathrm{a}$ & SM \\
\hline Perú & $2006 \cdot 2011$ & Alan García & $\begin{array}{c}\text { Partido Aprista Peruano } \\
\text { PAP }\end{array}$ & 36 & 30,0 & $\mathrm{n} / \mathrm{a}$ & $\mathrm{n} / \mathrm{a}$ & SM \\
\hline $\begin{array}{l}\text { República } \\
\text { Dominicana }\end{array}$ & $2000 \cdot 2004$ & Hipólito Mejía & $\begin{array}{c}\text { Partido Revolucionario } \\
\text { Dominicano }\end{array}$ & 71 & 47,7 & 28 & 90,6 & $U$ \\
\hline $\begin{array}{l}\text { República } \\
\text { Dominicana }\end{array}$ & $2004 \cdot 2006$ & $\begin{array}{l}\text { Leonel Antonio } \\
\text { Fernández Reyna }\end{array}$ & $\begin{array}{c}\text { Partido de la Liberación } \\
\text { Dominicana }\end{array}$ & 41 & 27,5 & 1 & 3,1 & SM \\
\hline Uruguay & $2000 \cdot 2004$ & Jorge Batlle & Partido Colorado & 33 & 33,3 & 10 & 32,2 & SM \\
\hline Uruguay & 2005-actual & Tabaré Vázquez & Frente Amplio & 52 & 52,5 & 16 & 51,6 & U \\
\hline Venezuela & $2005 \cdot 2006$ & Hugo Chávez & Movimiento Quinta & 114 & 68,3 & $\mathrm{n} / \mathrm{a}$ & $\mathrm{n} / \mathrm{a}$ & $U$ \\
\hline & & & República & & & & & \\
\hline Venezuela & 2006-actual & Hugo Chávez & $\begin{array}{l}\text { Movimiento Quinta } \\
\text { República y aliados }\end{array}$ & 167 & 100 & $\mathrm{n} / \mathrm{a}$ & $\mathrm{n} / \mathrm{a}$ & $U^{*}$ \\
\hline
\end{tabular}

SM Sin mayorías.

U Gobierno unificado.

n/a: No aplica porque son países unicamerales.

* Sin partidos de oposición representados en el congreso, dado que se retiraron en bloque en 2005 al desconfiar del sistema de recuento de la votación.

Fuente: Elaboración propia.

En el escenario político en América Latina predomina este tipo de gobierno y sólo Argentina, Chile, Colombia, Guatemala, Nicaragua, República Dominicana, Uruguay y Venezuela han experimentado un gobierno unificado en los últimos años. Lo relevante es que desde la oleada de democratización iniciada en la década de los setenta, la gran mayoría ha gobernado sin crisis constitucionales (CAREY, 1996/2005, p. 26) ${ }^{12}$.

El bloque de países de gobierno dividido por su parte, además de las dificultades de carecer de mayorías, su presidente ha tenido que afrontar limitados apoyos a nivel regional como en Brasil y México. El Partido dos Trabalhadores en Brasil, que llegó al poder con el 61,3 por ciento pero no ganó en los tres estados más importantes (Rio de Janeiro, Sao Paulo y Minas Gerais); Vicente Fox del Partido Acción Nacional en 2000 perdió el Distrito Federal, la ciudad más importante del país, además de que apenas gobernó su partido en siete entidades. Su sucesor, Felipe Calderón también de ese partido, gobierna nueve de 31 entidades del país, de las cuales en cinco no tiene mayorías y perdió también en el Distrito Federal.

Para continuar con el eje planteado inicialmente, esto es, qué elementos favorecen o limitan la capacidad de los presidentes para despejar su agenda política en gobiernos sin mayorías, se avanza enseguida, exponiendo que la fragmentación

\footnotetext{
12 Características muy peculiares son las del caso venezolano que, producto de una crisis institucional en su segundo mandato, ha llevado a neutralizar el papel de los partidos de oposición y a un reposicionamiento fuerte del presidente Chávez. Como un asunto de urgencia reglamentaria, en sus primeros días de su tercer gobierno, ha sometiendo ante la asamblea nacional una iniciativa de ley conocida como Proyecto de Ley Habilitante, en la que se reforma la constitución para otorgar al presidente poderes para legislar unilateralmente y por vía rápida en un lapso de año y medio. Diario El País, 20 de enero de 2007, España. El caso de Ecuador es también una nación que pervive en un clima de inestabilidad política.
} 
del sistema de partidos en la arena parlamentaria es también un indicador a considerar para definir los apoyos al presidente.

El número efectivo de partidos (NEP) en un sistema de partidos es clave para determinar su cooperación con el ejecutivo, pues si éste es multipartidista hay mayor dificultad de favorecer la cooperación entre el ejecutivo y el legislativo para forjar coaliciones de votación y aprobar los proyectos de ley. EI NEP es un indicador ya clásico, de LAAKSO y TAAGEPERA (1979) ${ }^{13}$, para ponderar el peso de cada partido en función de su tamaño en la arena electoral o parlamentaria. Es también funcional para definir el número real de jugadores que controlan los puntos de veto en la elaboración de las políticas públicas (NACIF, 2003, p. 4).

Para obtener los valores del NEP, se tiene en cuenta el número de escaños obtenidos por cada partido, luego de haberse celebrado las elecciones. El índice se calcula mediante la siguiente fórmula:

$$
\mathrm{NEP}=1 / \sum_{i=1}^{\mathrm{n}} p_{i}^{2}
$$

Donde pi es la proporción de escaños que tiene el $i$ partido con representación en la cámara de diputados. Los rangos de ponderación se retoman de la tipología de Sartori (1976/1999). Un sistema de partidos predominante es cuando el mismo partido gana continuamente la mayoría de las curules durante un período de varias décadas; uno bipartidista es cuando un partido obtiene una mayoría y gobierna sólo, no obstante que los partidos puedan alternarse en el gobierno; cuando el sistema de partidos tiene una baja polarización ideológica y con no más de cinco partidos relevantes, se está ante un multipartidismo moderado; y por último, el multipartidismo polarizado es cuando existe una alta polarización con más de cinco partidos relevantes.

La representación gráfica del NEP se observa en el Gráfico 2 que ilustra las dificultades de los presidentes de Bolivia, Brasil, Colombia, Ecuador y Venezuela para gobernar. Sus sistemas de partidos son multipartidistas polarizados. Particularmente el caso de Brasil que es el país con una representación que supera los siete partidos efectivos.

Brasil registra un número efectivo de partidos muy elevado y sin embargo el presidente Lula ha sido reelecto para un segundo mandato y no hay amenazas de cerrar el congreso o movilizaciones sociales como ha sucedido en Perú o Ecuador,

\footnotetext{
13 LAAKSO, M. y TAAGEPERA R. (1979) Effective Number of Parties: A Measure with Application to West Europe. Comparative Political Studies $\mathrm{n}^{\circ} 12$, p. 3-27.

Partido dominante cuando el NEP es menor de 1,7; bipartidista entre 1,8 y 24; multipartidismo moderado entre 2,5 y 3,9 y multipartidismo polarizado más de 4,0.
} 
países donde la crisis institucional no proviene de gobernar sin mayorías sino por la débil institucionalización de los procesos y agrupaciones políticas. Resultado de ello es que desde 1996 no ha cubierto un período completo de gobierno un presidente ecuatoriano.

En otros países como Honduras, Nicaragua, Panamá, Paraguay, República Dominicana y Uruguay no superan los tres partidos. En México, con la primera legislatura de Felipe Calderón se ha obtenido un NEP de 3,5 por lo que ha venido aumentado su polarización, y con ello las dificultades para encontrar consensos en la definición de las políticas. El promedio de América Latina en su conjunto es del 3,8 partidos efectivos. Es posible que entre más polarizado sea un sistema de partidos más se debilite el funcionamiento de sus instituciones, sin embargo, para comprobar esta hipótesis, habría que profundizar en el análisis con otras variables como el grado de disciplina de los partidos, que es también un criterio indispensable para determinar cuán eficaz puede ser el presidente en su administración.

\section{Gráfico 2. Número Eectivo de Partidos en la arena parlamentaria}

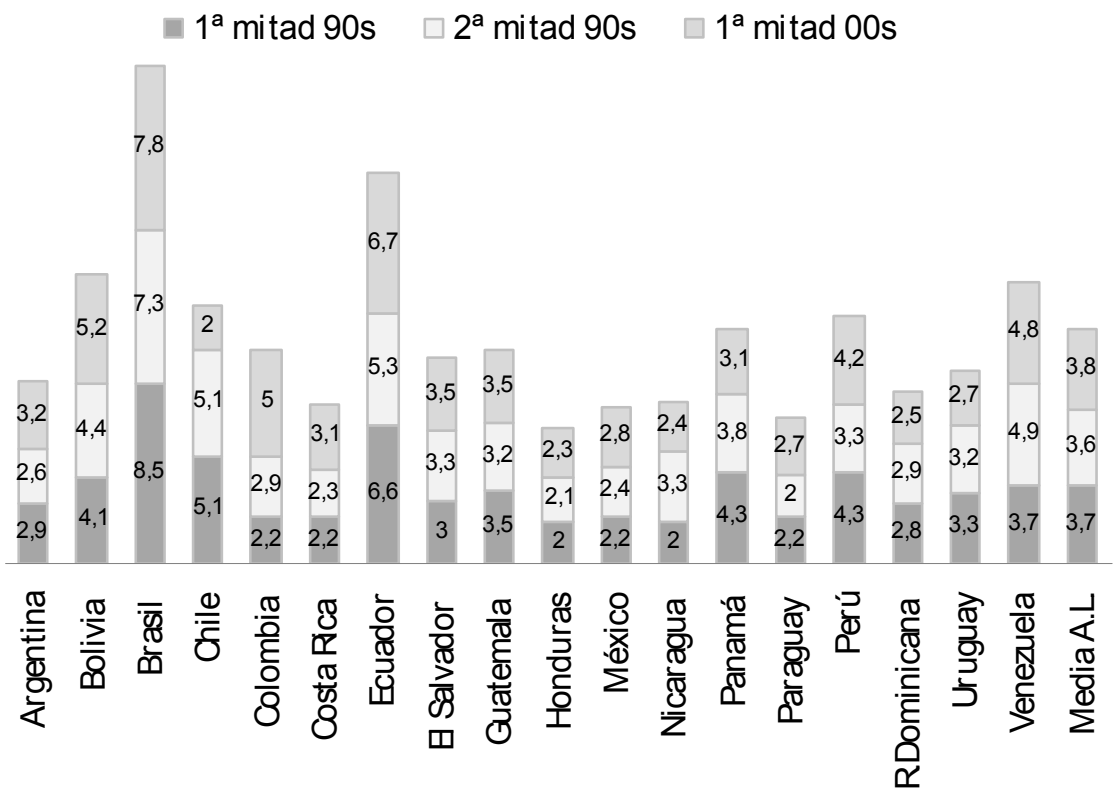

Fuente: Eaboración propia con datos de Al cántara y Frei denberg, 2001 p, 26 y Jones, 2005 citado en Stein et. al. (2006). 


\section{Estructuración ideológica de los sistemas de partidos}

Una pieza igualmente importante para determinar las capacidades presidenciales en llevar a cabo su programa de gobierno es la estructuración ideológica de los sistemas de partidos. Se considera aquí un predictor relevante que puede contribuir a definir cómo forjar alianzas interpartidarias en el congreso, pues la cooperación puede estar en razón del grado de polarización ideológica entre los partidos ${ }^{14}$. Entre más fragmentado es un sistema de partidos, más se dificultan los acuerdos en los trabajos parlamentarios, y se vuelve fácilmente vulnerable la relación entre ejecutivo y legislativo en tanto no puede haber acuerdos con partidos volátiles.

De ahí que los presidentes más exitosos - léase aquellos que han logrado la aprobación de sus iniciativas de ley en el congreso - se de en sistemas políticos más moderados, pues existen más posibilidades de consensos entre oposición y partido gobernante en la medida que se acercan más al centro del espectro político ${ }^{15}$. En contraparte, los sistemas de multipartidismo polarizado son los más vulnerables a problemas de ingobernabilidad y, sin embargo, sus instituciones políticas pueden funcionar como es e caso de Brasil.

Para determinar la estructuración ideológica del sistema de partidos se parte de las preferencias actitudinales de los partidos representados en el poder legislativo, las cuales son un indicador confiable para identificar la distancia ideológica entre éstos y así evaluar su disposición de coaligar entre sí para despejar la agenda política. Empíricamente, la estructuración ideológica puede medirse a partir de dos variables: autoubicación ideológica de los legisladores, esto es, la ubicación de diputado y la ubicación ideológica de su partido.

\footnotetext{
14 La polarización es entendida como la distancia o proximidad percibida por las elites políticas (en general, miembros del parlamento), en términos de cuán cercanos o alejados se sienten de los demás partidos, o bien la distancia que resulta de un análisis de contenido de plataformas electorales y/o de las posiciones ideológicas de los partidos" (SARTORI, 1976/1999, p. 424-428).

${ }^{15}$ Espectro político o eje espacial, que es una expresión simbólica de estructuración ideológica, una línea donde 1 es izquierda y 10 es derecha.
} 
Gráfico 3. Autoubicación y ubicación ideológica 2000-2006

(en medias)

$\rightarrow$-Ubicación Diputado —-Ubicación Partido
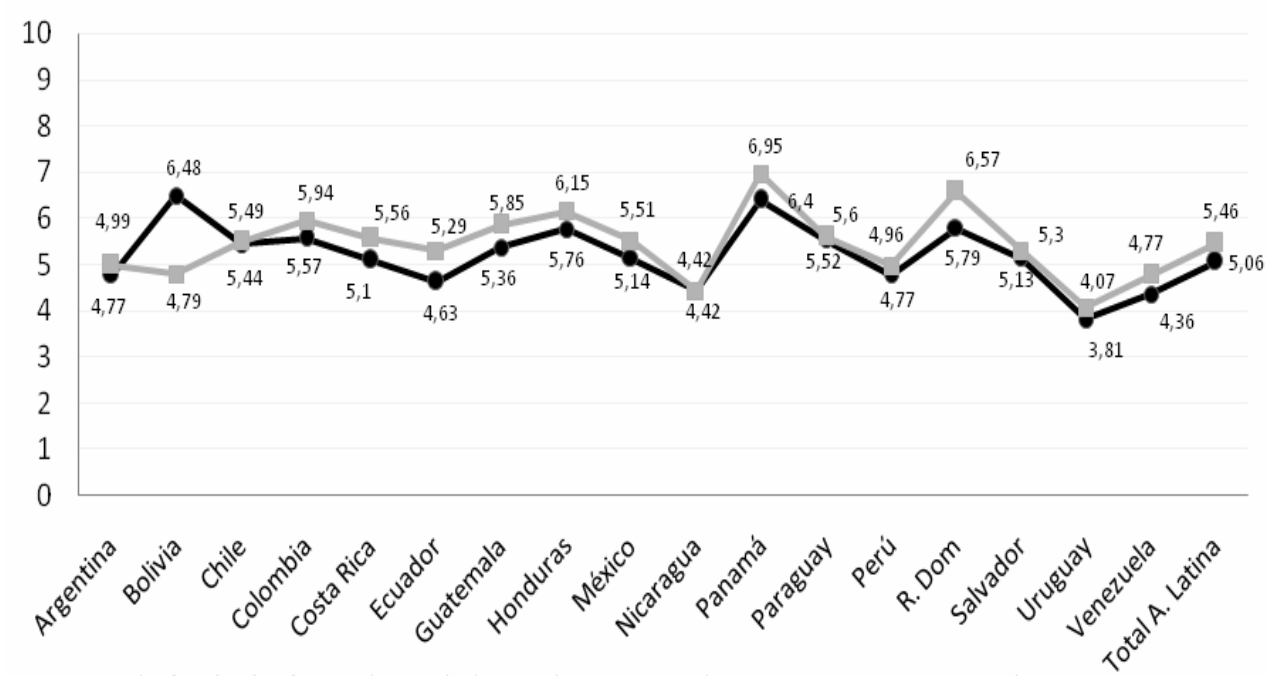

Fuente: Boletín Ideología y Valores de los parlamentarios latinoamericanos. Datos de opinión. Elites Parlamentarias Latinoamericanas. Instituto Interuniversitarios de Iberoamérica. Universidad de Salamanca.

A las preguntas hechas a cada legislador respecto a dichas variables ${ }^{16}$, el Gráfico 3 concentra el promedio de las medias por país entre 2000 y $2006^{17}$ y la lectura que arroja es que los sistemas de partidos en América Latina están identificados más en el centro del espectro ideológico, es decir, tienen una orientación centrípeta. La media total de los 17 países estudiados es de 5,06 en la ubicación del diputado y 5,46 en la ubicación de su partido ${ }^{18}$. El caso brasileño, que

\footnotetext{
16 Las preguntas realizadas fueron: "Cuando se habla de política se utilizan normalmente las expresiones izquierda y derecha. En una escala donde el 1 es izquierda y el 10 la derecha, ¿en qué casilla se colocaría usted teniendo en cuenta sus ideas políticas?". En la misma escala, ¿dónde ubicaría usted a su propio partido?

17 Las entrevistas fueron realizadas por el Equipo de Elites Parlamentarias del Instituto Interuniversitario de Estudios de Iberoamérica en el marco de los Proyectos de Elites Parlamentarias Latinoamericanas que han venido desarrollándose desde 1994 bajo la coordinación de Manuel Alcántara Sáez financiados por el "Plan Nacional Español de I + D".

18 Cuando el Latinobarómetro, en su Informe 2006, mide la posición ideológica de la población en la misma escala de izquierda a derecha da como resultado exactamente el mismo promedio de 5,4 que el que obtiene la Universidad de Salamanca al entrevistar a los legisladores, por lo que ambas fuentes concluyen que América Latina se encuentra en el centro político. Los electores, según el Latinobarómetro, se autoubican en la derecha en los países de: El Salvador, 50 por ciento; República Dominicana, 45 por ciento; Honduras, 44 por ciento, Colombia y Nicaragua, 43 por ciento. En cambio,
} 
no se expone en dicho Gráfico por contar sólo con parte de los datos, registra una media de 4,41 de ubicación de diputado, esto es, se autoubican en el centroizquierda del eje espacial.

Estas medias muestran una relativa coherencia entre las dos variables de estudio, y un ligero desplazamiento más a la derecha al ubicar a su partido. Analizando los datos por país, es claro que tanto Argentina, Brasil, Nicaragua, Perú, Uruguay y Venezuela son los países que se colocan más a la izquierda; mientras que los más identificados con la derecha son Honduras, Panamá y República Dominicana. El espectro ideológico del total de países no se localiza en la extrema derecha ni se observa una fuerte polarización en alguno de los países entre las dos variables de estudio, con lo cual se confirma que América Latina tiene sistemas de partidos moderados y de centro y centro-derecha ${ }^{19}$.

Las coaliciones interpartidarias se favorecen cuando existe una estrecha distancia ideológica entre los partidos, de tal suerte que es un componente factible para no dificultar los acuerdos institucionales. El partido mediano es el que determina la orientación de la votación, es decir, que, de acuerdo a su posición ideológica en el eje de izquierda-derecha, tiene tanto a su izquierda como a su derecha más o menos el mismo número de partidos en sus preferencias ${ }^{20}$.

Expuesto lo anterior, se hace necesario calcular la distancia ideológica de acuerdo a la noción de SARTORI (1976/1999, p. 433) ${ }^{21}$, a fin de evidenciar qué tan polarizado es el sistema de partidos en cada país, un indicador que apoya la hipótesis de que entre más cercanos se encuentren los partidos extremos desde el punto de vista ideológico, mayores posibilidades hay de construir coaliciones legislativas. Por el contrario, cuanto más distancia exista entre los dos partidos extremos, el presidente encontrará mayores dificultades para hacer aprobar sus iniciativas de ley (Tabla 4).

sólo Uruguay es el país con el más alto porcentaje de población identificada a la izquierda (34 por ciento).

19 Las posiciones actitudinales se agrupan considerando como izquierda a las medias ubicadas en los cuadrantes 1 y 2; centro-izquierda 3.4; centro 5.6; centro-derecha 7.8 y derecha cuando se autoubican entre las escalas de 9 y 10.

20 "La opción por la preferencia del votante mediano se basa en la propiedad aritmética de que la posición mediana, sea cual sea su localización en el espacio, minimiza la suma de las distancias con respecto a todas las demás posiciones. Dado que la 'proximidad' ha sido adoptada como el criterio básico de satisfacción, una política que coincida con la preferencia del votante mediano y minimice la suma de las distancias puede ser considerada como aquella que es capaz de producir una mayor satisfacción colectiva o utilidad social" (COLOMER y NEGRETTO, 2003, p. 15), que en este caso implicaría la factibilidad para aprobar las iniciativas de ley entre coalición gobernante y partidos de oposición.

21 "La distancia entre dos grupos cualesquiera, medida por la diferencia (absoluta) entre su autocolocación media dividida por el máximo teórico, que, en la escala izquierda-derecha en cuestión, es 9". 
BADILLO, M. J. Gobernando sin mayorias parlamentarias en América Latina....

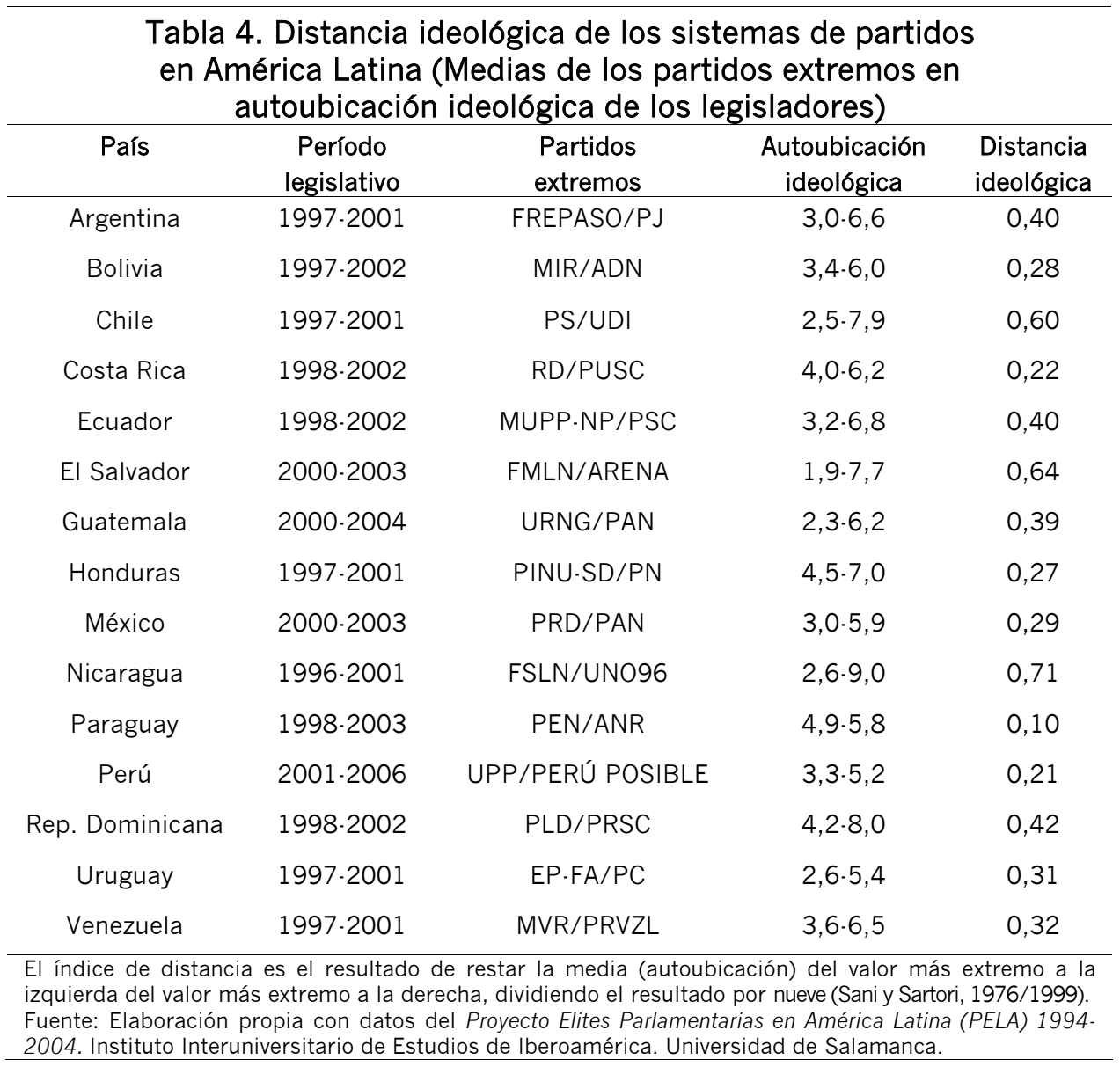

Cuando se obtiene una distancia más próxima a 0 representa una menor distancia ideológica entre dos partidos; y cuando está más cercana al 1 significa que hay mayor distancia ideológica. La coalición por tanto dependerá de la proximidad de la política que proponga el presidente y la política preferida por cada agrupación parlamentaria. Los resultados observables en la Tabla 4 muestran mayor polarización ideológica en Chile, El Salvador y Nicaragua.

A efecto de comprobar estadísticamente qué grado de coherencia ideológica existe entre la autoubicación y la ubicación ideológica, esto es, cómo se identifican los legisladores y cómo ven a su partido en el eje de izquierda a derecha, la Tabla 5 muestra la correlación de Pearson, distinguiendo una asociación altamente significativa para Chile, El Salvador, República Dominicana; mientras que las posiciones de menor coherencia ideológica se encuentran en México, Venezuela, Perú y Guatemala, lo cual denota un mayor distanciamiento entre los diputados y 
sus propios partidos. En el Salvador, por el contrario, se encuentra una mayor homogeneidad entre las dos variables, así lo refleja el índice $r=0,94(p \leq 0,01)$.

\begin{tabular}{|c|c|c|c|c|}
\hline \multicolumn{5}{|c|}{$\begin{array}{l}\text { Tabla 5. Correlación de Pearson en las variables autoubicación y ubicación } \\
\text { ideológica para los sistemas políticos de América Latina }\end{array}$} \\
\hline País & $\begin{array}{l}\text { Período } \\
\text { legislativo }\end{array}$ & Partidos & $\begin{array}{l}\text { Correlación } \\
\text { de Pearson }\end{array}$ & $\mathrm{N}$ \\
\hline Argentina & 1997.2001 & PJ/UCR/FREPASO/Provinciales & $0,76^{* *}$ & 122 \\
\hline Bolivia & 1997.2002 & ADN/MNR/MIR/UCS/ CONDEPA & $0,67^{* *}$ & 90 \\
\hline Chile & $1997 \cdot 2001$ & $\mathrm{DC} / \mathrm{RN} / \mathrm{UDI} / \mathrm{PPD} / \mathrm{PS}$ & $0,90 * *$ & 82 \\
\hline Costa Rica & 1998-2002 & PUSC/PLN/RD/PALA/PRC/PIN & $0,83^{* *}$ & 48 \\
\hline Ecuador & $1998-2002$ & PSC/DP/PRE/ID/MUPP.NP/PCE/PL & $0,85^{* *}$ & 107 \\
\hline El Salvador & $2000 \cdot 2003$ & FMLN/ARENA & $0,94^{* *}$ & 50 \\
\hline Guatemala & $2000 \cdot 2004$ & PAN/FRG/URNG/P UNIONISTA/UNE & $0,63^{* *}$ & 74 \\
\hline Honduras & $1997 \cdot 2001$ & PL/PN/PINU.SD/PDCH & $0,85^{* *}$ & 71 \\
\hline México & $2000 \cdot 2003$ & PAN/PRI/PRD & $0,46 * *$ & 116 \\
\hline Nicaragua & $1996 \cdot 2001$ & PL/FSLN/CCN/PCN/PRONAL/MRS/UN096 & $0,83^{* *}$ & 69 \\
\hline Paraguay & $1998 \cdot 2003$ & ANR/PLRA/PEN & $0,78^{* *}$ & 65 \\
\hline Perú & $2001 \cdot 2006$ & $\begin{array}{c}\text { UNIDAD NACIONAL/FIM/PAP/UPP/PERÚ } \\
\text { POSIBLE }\end{array}$ & $0,62^{* *}$ & 74 \\
\hline Rep.Dominicana & 1998-2002 & $\mathrm{PRD} / \mathrm{PLD} / \mathrm{PRSC} / \mathrm{BIP}$ & $0,89 * *$ & 97 \\
\hline Uruguay & $1997 \cdot 2001$ & $\mathrm{EP} \cdot \mathrm{FA} / \mathrm{PC} / \mathrm{PN} / \mathrm{NE}$ & $0,88^{* * *}$ & 66 \\
\hline Venezuela & $1997 \cdot 2001$ & MVR/AD/MAS/COPEI/PRVZL & $0,60^{* *}$ & 85 \\
\hline
\end{tabular}

Sin embargo, al pedir a los miembros del congreso en cada país que ubiquen ideológicamente a otros partidos diferente al suyo, los promedios por partido dan resultados que reflejan un escenario político en el que predomina la derecha, es decir, el escenario ideológico no es ya centrípeto sino que está más polarizado hacia la extrema derecha, aunque otros partidos son considerados más de centro y en menor medida, otros, a la izquierda (Tabla 6). 
Tabla 6. Ubicación media de cada partido según las percepciones de los otros partidos en los congresos de América Latina (donde 1 es izquierda y 10 es derecha)

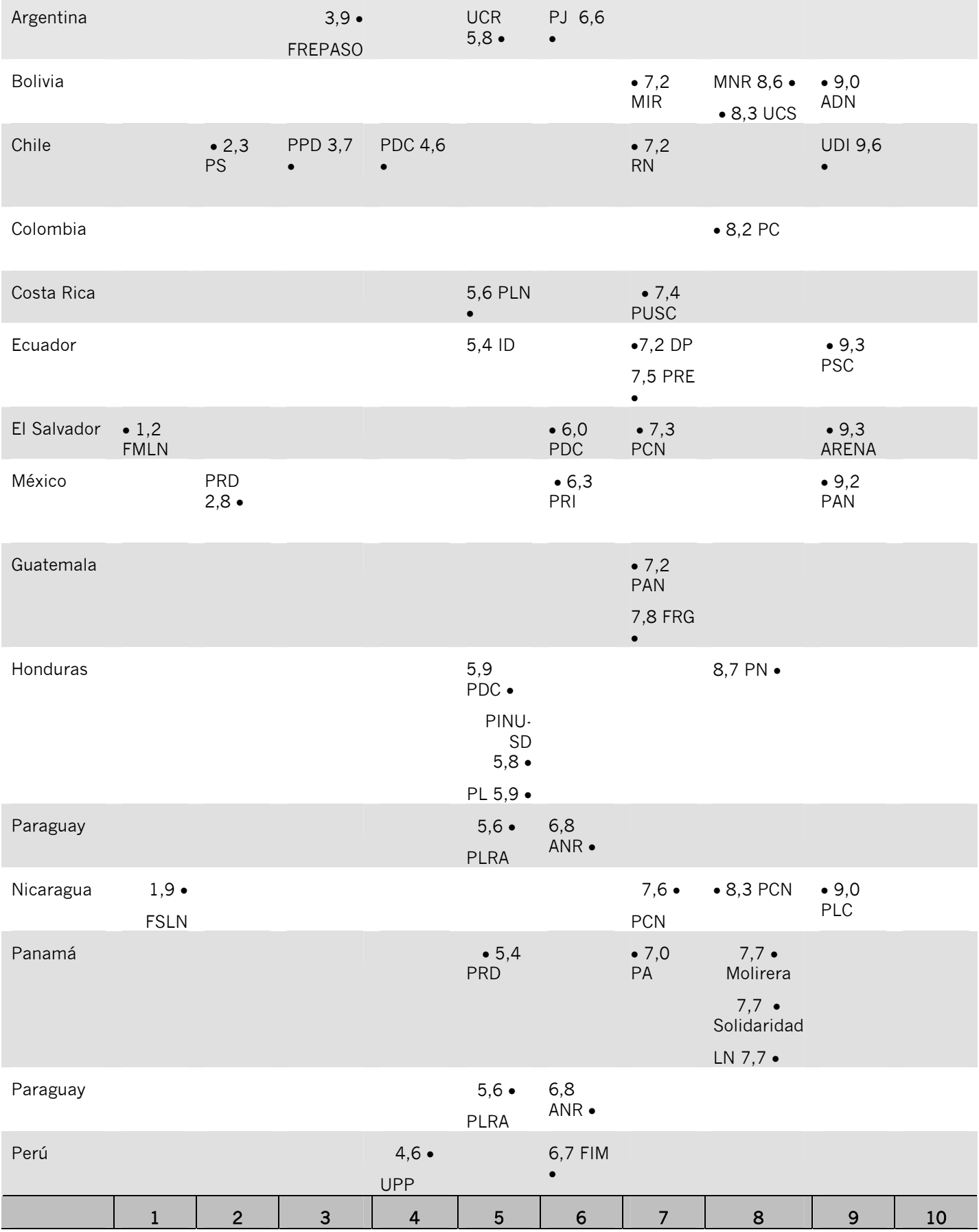


OPINIÃO PÚBLICA, Campinas, vol. 13, nº 1, Junho, 2007, p.149-185

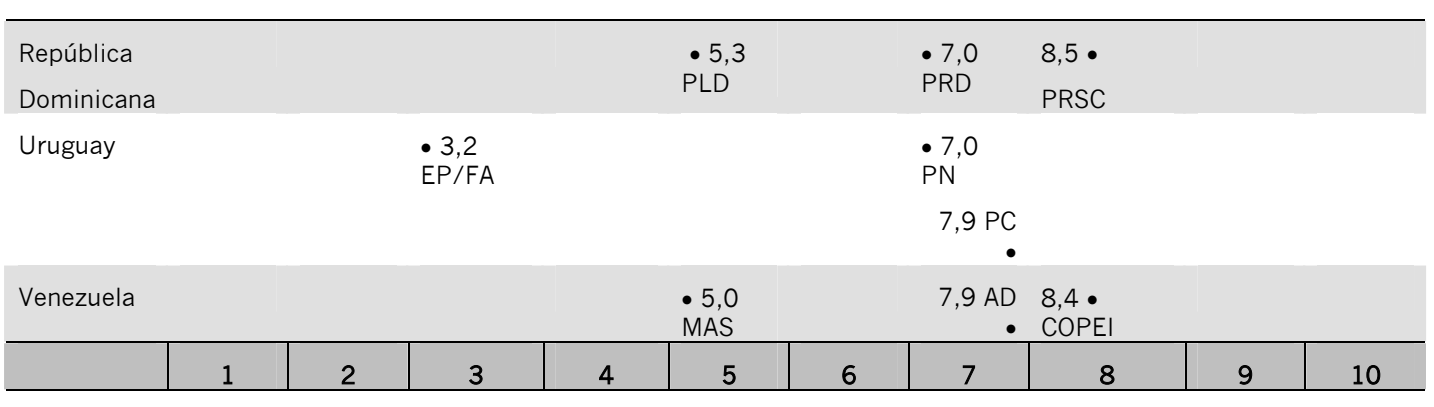

Pregunta realizada: "Cuando se habla de política se utilizan normalmente las expresiones izquierda y derecha. En una escala donde el 1 es izquierda y el 10 la derecha, ¿en qué casilla colocaría usted a los siguientes partidos?"

Fuente: Elaboración propia con datos de: Boletines de Opinión Elites Parlamentarias Latinoamericanas para cada país, editados por el Instituto Interuniversitario de Estudios de Iberoamérica. Universidad de Salamanca.

Una estrategia presidencial para superar la polarización es que en la práctica se busca establecer apoyos de otros partidos para constituir coaliciones en la arena parlamentaria. Es el caso de Argentina con Kirchner quien, no obstante que tuvo mayoría absoluta en ambas cámaras con el partido Justicialista en 2005, la oposición mantuvo el control del 49 por ciento de los escaños en la cámara baja y el 43 por ciento en el senado, de los cuales un tercio fueron de orientación ideológica de derecha y cercanos a Carlos Menem. Así, la estrategia del presidente Kirchner fue la transversalidad, es decir buscar apoyo político mediante la cooptación de líderes partidarios y sociales fuera del Partido Justicialista (AMORIM NETO, 2004).

Desde cualquiera de estas rutas, lo relevante es la presencia protagónica de los partidos de oposición en la arena parlamentaria. La proclividad de los partidos para acotar los mecanismos institucionales del presidencialismo exacerbado de antaño (Argentina, México) es el atributo rescatable de los escenarios sin mayorías que tiene que afrontar la institución presidencial. Tal es uno de los atributos que abona elementos favorables para el funcionamiento adecuado de las democracias en América Latina.

Las percepciones actitudinales de autoubicación y ubicación ideológica nos han permitido demostrar que en América Latina existen sistemas de partidos moderados $y$, en menor grado, otros países con sistemas polarizados y que la noción distancia ideológica es confiable para determinar qué tan distantes o próximos. Oportuno es plantearnos ahora en qué medida los diputados compiten por las mismas localizaciones espaciales. Es decir, en qué medida su plataforma programática, principios y valores son coincidentes en una variedad de temáticas de tal forma que puedan diluir el conflicto. Para este fin, se calcula el grado de superposición existente entre los partidos, que no es sino la media en que los 
miembros de los partidos ocupan las mismas posiciones en la escala izquierdaderecha ${ }^{22}$.

La superposición es aplicada aquí sólo al sistema de partidos de México a manera de ejemplo. Ésta puede representarse mediante nichos ideológicos para cada partido, los cuales son áreas que se conforman para caracterizar pares de partidos. La superposición entre dos partidos permite valorar qué tan condicionada se encuentra la disposición de cada uno para cooperar en su desempeño legislativo. Son espacios cuadrados o rectangulares que "ayudan a establecer cómo el espacio ideológico constriñe y condiciona la competición y la cooperación entre los partidos políticos" (LLAMAZARES y SANDELL, 2001, p.48).

La configuración de los nichos se realiza mediante sus percepciones de cómo se sienten ideológicamente (autoubicación) y cómo ven a su partido (ubicación), agrupadas en los cinco segmentos del continuum espacial. Su tamaño se define tanto con las medias de estas variables como por sus desviaciones típicas.

La Tabla 7 concentra las medias y desviaciones típicas para la configuración de los nichos ideológicos por cuanto a su tamaño y superposición ${ }^{23}$. En la última columna se muestra qué tan grande es el traslape entre pares de partidos, calculado en porcentajes.

\footnotetext{
22 El índice de superposición entre dos partidos se calcula comparando los porcentajes de casos situados en cada uno de los cinco segmentos del continuum. Se obtiene dividiendo la suma (absoluta) de las diferencias por el máximo teórico (es decir, 200, ya que cada línea suma 100) y sustrayendo el resultado de 1 (SANI y SARTORI 1976/1999, p. 432.433)

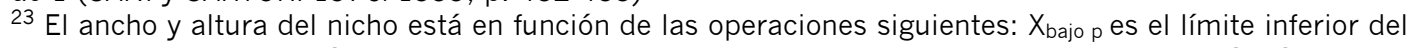
partido $p$ en la dimensión $x$; $\mu_{x p}$ es el valor medio en $x$ para el partido $p ; \sigma_{x p}$ es la desviación típica en $x$ para el partido $p$; $X_{\text {alto }}$ es el límite superior de ese nicho.
} 
Tabla 7. Nichos ideológicos y traslapes de los partidos políticos según su posición en una dimensión de izquierda-derecha. Cámara de Diputados de México

\begin{tabular}{|c|c|c|c|c|c|c|c|c|c|c|}
\hline \multirow{2}{*}{$\begin{array}{l}\text { legislaturas } \\
2000 \cdot 2003\end{array}$} & \multicolumn{3}{|c|}{$\begin{array}{c}\text { Autoubicación de los } \\
\text { Legisladores }\end{array}$} & \multicolumn{3}{|c|}{$\begin{array}{l}\text { Ubicación de los } \\
\text { partidos }\end{array}$} & \multirow{2}{*}{$\begin{array}{l}\text { Nicho } \\
\text { Tamaño }\end{array}$} & \multicolumn{3}{|c|}{$\begin{array}{c}\text { Traslape } \\
\text { (porcentajes) }\end{array}$} \\
\hline & $\mu$ & $\sigma$ & Nicho & $\mu$ & $\sigma$ & Nicho & & PRI & PAN & PRD \\
\hline PRI & 4,71 & 1,44 & 2,88 & 5,25 & 1,18 & 2,36 & 6,79 & 00 & 22,7 & 18,8 \\
\hline PAN & 5,88 & 1,16 & 2,32 & 6,38 & 1,03 & 2,06 & 4,77 & 32,3 & 00 & 00 \\
\hline PRD & 3,08 & 1,08 & 2,16 & 4,18 & 1,32 & 2,64 & 5,70 & 22,3 & 00 & 00 \\
\hline \multicolumn{11}{|c|}{$\begin{array}{l}\mu=\text { medias; } \sigma=\text { desviación típica } \\
\text { Operacionalización de los datos para calcular los nichos ideológicos se eje } \\
\text { PRI autoubicación } \\
X_{\text {bajo } p}=\mu_{x p}-\sigma_{x p}: 4,71-1,44=3,27 \text { (límite inferior de autoubicación) } \\
X_{\text {alto } p}=\mu_{x p}+\sigma_{x p}: 4,71+1,44=6,15 \text { (límite superior de autoubicación) } \\
X_{p}=X_{\text {alto }} \cdot X_{\text {bajo } p}: 6,15-3,27=2,88 \text { (nicho) }\end{array}$} \\
\hline \multicolumn{11}{|c|}{$\begin{array}{l}X_{\text {bajo }}=\mu_{x p}-\sigma_{x p}: 5,25 \cdot 1,18=4,07 \text { (límite izquierdo) } \\
X_{\text {alto } p}=\mu_{x p}+\sigma_{x p}: 5,25+1,18=6,43 \text { (límite ancho derecho) } \\
X_{p}=X_{\text {alto }} \cdot X_{\text {bajo }}: 6,43-4,07=2,36 \text { (nicho) } \\
\text { El área del nicho: } 2,88 * 2,36=6,79\end{array}$} \\
\hline \multicolumn{11}{|c|}{$\begin{array}{l}X_{\text {bajo } p}=\mu_{x p}-\sigma_{x p}: 5,88 \cdot 1,16=4,72 \text { (límite inferior de autoubicación) } \\
X_{\text {alto } p}=\mu_{x p}+\sigma_{x p}: 5,88+1,16=7,04 \text { (límite superior de autoubicación) } \\
X_{p}=X_{\text {alto }} p \cdot X_{\text {bajo } p}: 7,04-4,72=2,32 \text { (nicho) }\end{array}$} \\
\hline \multicolumn{11}{|c|}{$\begin{array}{l}X_{\text {bajo } p}=\mu_{x p}-\sigma_{x p}: 6,38-1,03=5,35 \text { (límite ancho izquierdo) } \\
X_{\text {alto } p}=\mu_{x p}+\sigma_{x p}: 6,38+1,03=7,41 \text { (límite derecho) } \\
X_{p}=X_{\text {alto }} \cdot X_{\text {bajo }}: 7,41-5,35=2,06 \text { (nicho) } \\
\text { El área del nicho: } 2,32 * 2,06=4,77\end{array}$} \\
\hline \multicolumn{11}{|c|}{$\begin{array}{l}\text { Solapamiento entre los nichos del PRI y el PAN: } \\
615-4,72=1,43 \\
6,43-5,35=1,08 \\
1,43 * 1,08=1,54 \\
1,54 / 6,79=22,6 \% \\
1,54 / 4,77=32,3 \%\end{array}$} \\
\hline Fuente: Elabora & in propic & & & & & & & & & \\
\hline
\end{tabular}

Los nichos ideológicos, teóricamente caracterizan pares de agrupaciones políticas. Cuando no hay solapamiento entre dos partidos significa que no hay competencia entre sí (HANNAN, CARROLL y PÓLOS, 2003, p. 3). En contraparte, cuando compiten por un mismo espacio, se superponen en la dimensión de izquierda a derecha. Al ser sobrepuestos o traslapados, describe las organizaciones que compiten entre miembros similares (McPHERSON, 1983) o bien, en el contexto 
electoral, es cuando las organizaciones compiten por miembros de la misma población (LOVELAND, 2001, p. 24).

Figura 1

Nichos ideológicos en la Cámara de Diputados

(LVIII Legislatura, 2000-2003)

Autoubicación ideológica

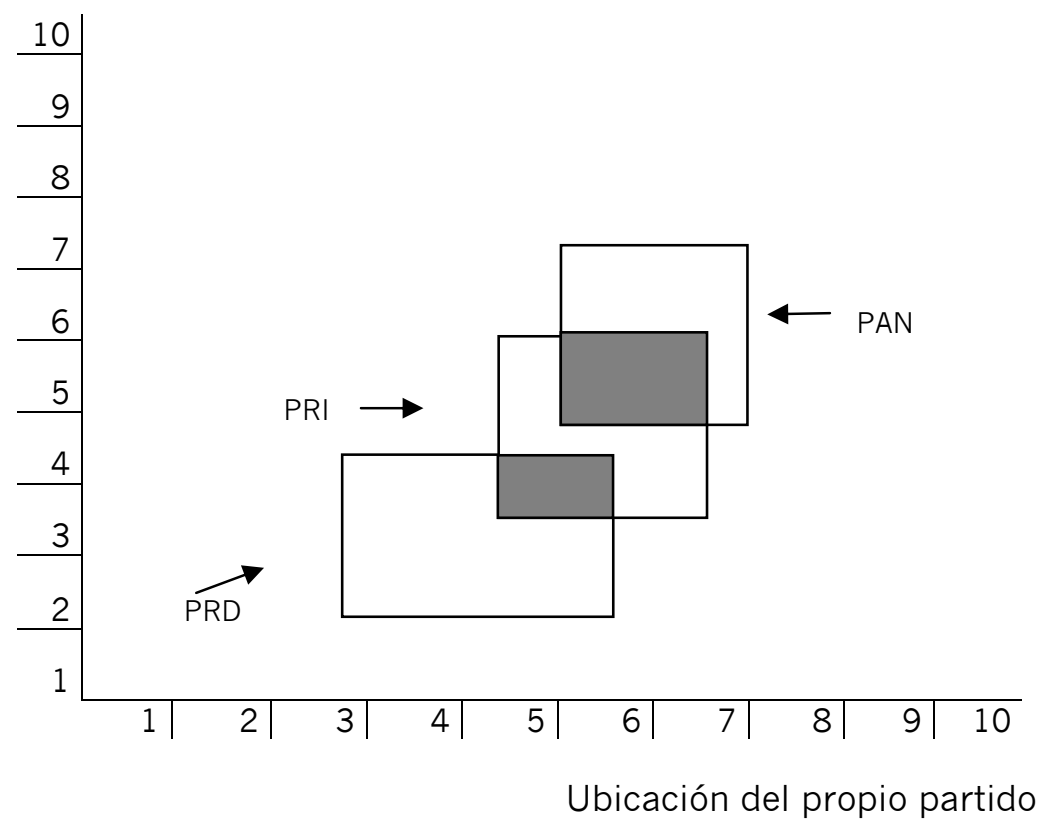

Fuente: Elaboración propia a partir de Llamazares y Sandell (2001).

EI PRD es el único partido que tiene su propia definición ideológica, esto es, no compite con los otros partidos sus valores y principios ideológicos. Este espacio menos competido se observa en el traslape que tiene con el PRI (área sombreada). Un espacio que ambos comparten y que es más reducida que la que comparten el PRI y el PAN. En todo caso, la Figura corrobora que el sistema de partidos en México es moderado ya que las tres principales agrupaciones tienden a concentrarse en el centro del eje espacial de izquierda a derecha. El PRI que está más al centro comparte ciertos valores con el PRD pero éste partido con el PAN no tiene convergencia alguna porque ambos nichos están distantes. 
La Figura 1 también ratifica que a mayor distancia y menor superposición más alto es el grado de polarización ideológica. Tal es el caso del PRD y el PAN. En otros términos, las mayores dificultades para cooperar y llegar a acuerdos en la arena parlamentaria están entre el PRD y el PAN ${ }^{24}$.

\section{Producción legislativa de la institución presidencial}

Queda por resolver el grado de éxito presidencial en materia de producción legislativa. En otros términos, si su agenda propuesta al congreso le es aprobada por éste, tanto en los gobiernos unificados como en los gobiernos sin mayorías parlamentarias. El caso argentino es sintomático por su reconocida aprobación de Kirchner frente a un sistema de partidos con escaso margen de credibilidad, especialmente en los últimos años, luego de la crisis económica de 2001.

Kirchner, de 2003 a 2006 ha orientado su política gobernando por decreto y, en menor medida, enviando iniciativas de ley al congreso ${ }^{25}$. La práctica presidencial de gobernar por decretos de necesidad y urgencia (DNU) se ha institucionalizado como un ejercicio común y aceptable entre las elites de decisión política. Esto significa que el presidente asume las facultades propias del congreso, que son dictar normas con rango de ley, modificarlas o derogarlas ${ }^{26}$. De las emitidas en mayo 2005 a mayo 2006, que fueron un total de 61, alrededor de 35 se refieren a políticas públicas como jubilaciones, subsidios, asignaciones familiares, indemnizaciones, así como 22 fueron relativas a la ley de presupuesto, los fondos fiduciarios y la deuda pública, y ratificaciones de acuerdos y tratados internacionales, es decir, son temas de carácter ordinario que sin menos cabo pasan en el congreso (Tabla 8).

\footnotetext{
24 Teniendo en cuenta los dos índices de Distancia y el de Superposición, el par PRI-PAN tiene un 0,13 y 0,76 respectivamente. El par PRI-PRD un 0,18 de distancia y 0,44 de superposición y el par PAN-PRD un 0,31 y 0,19 . Es decir, son más distantes ideológicamente y en consecuencia su traslape es menor.

${ }^{25}$ Los decretos de necesidad y urgencia (DNU) fueron resultado de una reforma constitucional en 1994, en la que se otorgó al presidente la facultad de dictar leyes sólo "cuando circunstancias excepcionales hicieren imposible seguir los trámites ordinarios previstos por la Constitución" (artículo 99). FERREIRA y GORETTI (2006) consideran que dichos decretos sólo se justifican en caso de crisis extrema, la necesidad de sancionar un tema resistido por la ciudadanía o un congreso cerrado o con el oficialismo en minoría. Sin embargo, Kirchner ha seguido esta política preferencial de decreto y no canalizar sus iniciativas al congreso aún cuando tuvo mayoría absoluta en el parlamento y sin un escenario de crisis económica extrema.

26 Este comportamiento político de los poderes ejecutivo y legislativo en Argentina contradice la tesis sostenida aquí, en lo general respecto a América Latina respecto al rol proactivo que están asumiendo los congresos porque su mayor presencia en escaños le otorga recursos para influir en la elaboración de las políticas públicas.
} 
Tabla 8. El presidente legisla por Decreto en Argentina (2003-2006)

\begin{tabular}{ccc}
\hline Período & $\begin{array}{c}\text { Iniciativas enviadas al congreso } \\
\text { (Proyectos de ley) }\end{array}$ & $\begin{array}{c}\text { Decretos de Necesidad y } \\
\text { Urgencia (DNU) }\end{array}$ \\
$2003-2004$ & 56 & 67 \\
$2004-2005$ & 45 & 73 \\
$2005-2006$ & 57 & 61 \\
Total (Iniciativas y DNU) 359 & $158(44 \%)$ & $201(56 \%)$ \\
\hline Fuente: Elaboración propia con datos de Delia Ferreira Rubio y Matteo Goretti (2006). Estudio del Centro de Estudios de \\
\hline
\end{tabular}

Los DNU se refieren principalmente a temas relativos al presupuesto. Si bien es un rubro muy sensible y en el que por regla general los congresos intentan mayor protagonismo respecto al ejecutivo pretendiendo imponer su criterio, es notable que el presidente tuvo por preferencia asegurar su agenda de gobierno mediante este canal y no sujetándose al férreo control político que implica pasarlas por el congreso, máxime cuando un tercio de los diputados estaban definidos más hacia el nemenismo, aunque ha tenido un contingente favorable controlando 34 de 45 comisiones ordinarias en la Cámara baja y 19 de 24 en el senado. En otras palabras, el papel que Kirchner ha jugado es desplazar de sus funciones al congreso, pues con los DNU que no son de urgencia, ha asumido facultades propias del congreso.

Se trata de una práctica común desde Carlos Menem, quien en sus diez años de gobierno decretó 545 DNU (54,5 por año). La interpretación de estos procesos está en razón de que prevalecen en Argentina los resabios del hiperpresidencialismo de antaño, donde la concentración del poder en la institución presidencial era parte de la política cotidiana. Kirchner sigue esta estrategia para asegurar la concreción de su agenda política y su partido argumenta que es válido el procedimiento de legislar por decreto, una prerrogativa que en estos días está siendo revisada por el senado para modificar su contenido y otorgar su lugar de legislador al congreso.

En Argentina, las iniciativas prioritarias surgen de la presidencia; en México también, sin embargo, el presidente mexicano no tiene el poder de decreto-ley que tiene Argentina, Brasil con las medidas provisórias y en Venezuela desde febrero 2007 cuando se aprobó la Ley Habilitante que consiste en otorgar a Chávez la facultad de decretar en un lapso de 18 meses para impulsar sus políticas ${ }^{27}$.

\footnotetext{
${ }^{27}$ La asamblea que está integrada sólo por diputados oficialista autorizó el 31 de enero de 2007 que el presidente tuviera capacidad para emitir decretos de ley en once campos: transformación del Estado; participación popular; ejercicio de la función pública; seguridad ciudadana y justicia; ordenación territorial; seguridad y defensa; infraestructura, transporte y servicios; económico y social; financiero y tributario; ciencia y tecnología; y energético.
} 
El éxito del presidente mexicano es alto porque su porcentaje de iniciativas aprobadas en relación a las presentadas fue de un 90,5 por ciento en las dos legislaturas del sexenio de Ernesto Zedillo (1994-2000); mientras que Vicente Fox alcanzó un 75 por ciento de éxito ${ }^{28}$. Estos datos sin embargo corresponden al total de iniciativas presentadas, sin distinguir ordinarias o prioritarias, por lo que no puede concluirse que Fox haya tenido un muy alto éxito en su agenda política ya que quedaron aplazadas para negociación y acuerdos, las reformas estructurales que consideró prioritarias en su gestión pública ${ }^{29}$.

En Argentina y en México, los presidentes en la práctica han sido dominantes para fijar la agenda política tanto en un contexto de gobierno unificado como en los gobiernos sin mayorías. Si bien se han reducido sus prerrogativas pragmáticas o reglas no escritas, al prevalecer un contingente mayor de oposición en la arena parlamentaria no han reducido su éxito en hacer aprobar sus iniciativas de ley, o ha disminuido muy ligeramente en el marco en el que desarrolla su función, que es el de un presidencialismo más acotado porque la institución presidencial ha visto reducida la concentración del poder político.

Datos menos recientes muestran en otros países latinoamericanos la tasa de éxito presidencial en la aprobación de sus iniciativas (Tabla 9). Nótese que tratándose de gobiernos unificados o sin mayorías los presidentes han logrado coaliciones interpartidarias en el congreso para definir su agenda legislativa.

\footnotetext{
28 En el primer período sin mayorías en México (1997-2000) el presidente tuvo un éxito del 82 por ciento de sus iniciativas que presentó en el congreso; en el período de 2000 a 2006, que implica todo el sexenio de Vicente Fox, y caracterizado por gobierno sin mayorías, el presidente presentó al congreso 162 iniciativas de ley o decreto, de las cuales se le aprobaron 121, esto es, el 74,8 por ciento.

29 Intenso debate e imagen pública suscitaron las propuestas de Vicente Fox para grabar impuesto a artículos de primera necesidad, así como medicamentos, libros y revistas. El impuesto al valor agregado fue una de sus propuestas prioritarias, así como atender la reforma fiscal, laboral y privatización de la energía eléctrica. Tales temas de agenda denominados reformas estructurales no fueron desahogados en el congreso en ninguna de las dos legislaturas de su gestión. Desde la óptica de la oposición, cooperar con el presidente les representaba mayores costos políticos, resultando insuficientes los incentivos para definir sus preferencias ideológico-programáticas a favor de dichos proyectos. Ningún partido de oposición sacrificó votos electorales al aproximarse las elecciones intermedias de julio 2003 y después las presidenciales de 2006.
} 
BADILLO, M. J. Gobernando sin mayorias parlamentarias en América Latina....

Tabla 9. Tasa de aprobación de las iniciativas propuestas por el poder ejecutivo

\begin{tabular}{ccc}
\hline País & Período & Porcentaje \\
\hline México & $1982 \cdot 1999$ & 96 \\
Paraguay & $1990 \cdot 1999$ & 83 \\
Honduras & $1990 \cdot 1996$ & 79 \\
Chile & $1990 \cdot 2000$ & 69 \\
Venezuela & $1958 \cdot 1988$ & 68 \\
Perú & $2001 \cdot 2004$ & 65 \\
Argentina & $1983 \cdot 2000$ & 64 \\
Uruguay & $1985 \cdot 2000$ & 57 \\
Ecuador & 1979.1996 & 42 \\
Costa Rica & $1986 \cdot 1988$ & 41 \\
\hline
\end{tabular}

Fuente: Stein, et. al. (2006)

Las tasas más reducidas corresponden a Ecuador y Costa Rica a final de los años noventa. Sin embargo, el México todavía hegemónico que sufría en ese período la debacle de crisis económica o "la década perdida" fue el que alcanzó una tasa de éxito muy superior a otros países.

En Chile, parece seguirse el mismo patrón de predominar más la agenda del presidente que la de los legisladores. Durante el gobierno de Aylwin (1990-1993), el ejecutivo alcanzó una tasa del 91,8 por ciento de sus iniciativas aprobadas, mientras los legisladores apenas lograron ver aprobadas el 8,2 de sus iniciativas (SIAVELIS, 2001). El mismo autor analiza el período de Eduardo Frei (1994-1997) en donde el ejecutivo vio un éxito del 75,1 frente al 25 por ciento de los legisladores. Aún cuando se contaba con mayorías parlamentarias los datos no reflejan un ejecutivo muy exitoso, por lo que no necesariamente en los gobiernos sin mayorías es donde se dan tasas disminuidas de éxito presidencial.

Oportuno es tener en consideración que en el presidencialismo latinoamericano, como en el caso chileno, e igualmente en México, cuando la agenda política presidencial no es atendida en tiempos por el congreso, el ejecutivo no tiene ningún mecanismo de sanción y el congreso puede prorrogar el análisis, o incluso no hacerlo, de las iniciativas presidenciales. Así, en el gobierno de Aylwin, si bien alcanzó una tasa elevada de aprobación, el proceso para llegar a esta fase fue muy lento en casi todas las iniciativas presidenciales dictaminadas.

A Ricardo Lagos se le aprobó el 64 por ciento de sus iniciativas presentadas, frente al 36 por ciento de los legisladores. Un factor favorable al ejecutivo que "concentra una enorme masa de capacidad técnica que le permite mejores oportunidades para imponer sus iniciativas legislativas. Cada ministerio posee su propia técno-estructura, que lo habilita como co-legislador en su propia área. La presidencia, a través de su secretaría general - que tiene rango de ministerio - no solamente coordina la elaboración de los proyectos de leyes, sino también su 
presentación constitucional y la estrategia que en cada caso conviene seguir en el congreso" (GODOY, 2003) ${ }^{30}$.

Lo anterior es apenas un indicador que muestra la fortaleza de la institución presidencial en los gobiernos tanto unificados como sin mayorías y, si bien en éstos últimos se favorece el presidencialismo más acotado, se da una división de poderes más equilibrada. Por tanto, los gobiernos sin mayorías y su producción legislativa no parecen ser variables que generen ingobernabilidad en América Latina, y en cambio sí sigue pendiente el análisis cualitativo de qué tipo de leyes son las que se aprueban, esto es, si son protocolarias, de permisos presidenciales para viajar al exterior, o son iniciativas de mayor impacto social que se convierten en políticas de gobierno. Sigue quedando como agenda pendiente también evaluar qué tanto aporta esa actividad legislativa a la calidad de la democracia, prioridad que merece un estudio más minucioso.

\section{Reflexiones finales}

Una particularidad de los gobiernos de mayoría dividida es la posibilidad de una competencia entre partidos, institucionalizando el disenso en donde las fuerzas de oposición adquieren un valor cualitativo para la consolidación de la democracia. Se ha transitado de la inexistencia de partidos en los regímenes autoritarios al reconocimiento de éstos como instancias de intermediación de los intereses sociales, que si bien tienen un rango de credibilidad muy limitado, siguen siendo la expresión más acabada de voz ciudadana, y la articulación del conflicto que tiene su cause en la negociación entre los actores políticos y no las decisiones verticales y autoritarias que se dieron en los tiempos de dictadura.

La ausencia de mayoría absoluta en el congreso del partido o coalición gobernante puede propiciar el equilibrio de poderes; es un aspecto determinante para que las instituciones asuman nuevas actitudes, nuevas formas de hacer política con la sensibilidad de renovarse adoptando acciones de gobierno para la implementación de políticas públicas que reporten beneficios sociales a una colectividad y no que favorezcan intereses de minorías.

Con gobiernos sin mayorías es más factible valorar el papel del Poder legislativo como instancia con capacidad decisoria en la elaboración de políticas. De este cuerpo legislativo salen aprobadas las leyes que son remitidas al ejecutivo para su decreto y puesta en marcha. Se ha avanzado en ir superando la imagen de

\footnotetext{
30 El mismo autor hace un recuento del trabajo legislativo de 1990 a 2003, donde se registran 962 leyes aprobadas y promulgadas, de las cuales 725 se originaron en el poder ejecutivo y 237 en el congreso. Esto es, 75,3 por ciento provienen de la presidencia y sólo 24,6 por ciento de los legisladores.
} 
congresos débiles, sumisos y reactivos como podría leerse con la evidencia empírica de que en Argentina, México, Chile y otros países sigue siendo el ejecutivo el de mayor éxito en la aprobación de sus iniciativas. El rol legislativo no está únicamente en la producción legislativa, su influencia y rol de representación de los intereses ciudadanos, son indispensables en la rendición de cuentas, en bloquear también ambiciones personalistas del presidente, en influir mediante enmiendas en las propuestas del ejecutivo, entre otras funciones.

Para el caso mexicano, no ha habido disfunción en el papel de las instituciones. Los distintos partidos políticos han conformado coaliciones de votación para aprobar los proyectos de ley del ejecutivo. De 1997 a 2000, concurrieron partidos de oposición y gobernante para construir coaliciones de votación en el 46,8 por ciento de las iniciativas aprobadas durante toda la legislatura. Asimismo, de 2000 a 2003, la gran coalición donde concurrieron todas las fuerzas políticas se dio en el 76,8 por ciento de las iniciativas aprobadas (JIMÉNEZ, 2006). Estos datos demuestran que sí hay acuerdos entre partido de gobierno y partidos opositores.

En las tres legislaturas sin mayorías en México (1997-2000; 2000-2003 y 2003-2006) no se ha puesto en riesgo la gobernabilidad porque se hayan bloqueado los proyectos presidenciales. La actual legislatura que pudo despertar suspicacias de que el PRD bloquearía al presidente Calderón por la falta de claridad en su triunfo electoral, y sin embargo, se han forjado coaliciones, votan juntos asumiendo un papel proactivo en la producción legislativa.

Así, el comportamiento político de los poderes ejecutivo-legislativo se ha venido articulado mediante la cooperación manifestada en la disposición de las fuerzas políticas para construir coaliciones y despejar la agenda política, aún cuando los contenidos de las enmiendas a las propuestas presidenciales que haga la oposición, no sean óptimas para la presidencia. La tesis de Linz de que al no contar el partido del presidente con el apoyo mayoritario en el legislativo, los partidos de oposición carecen de incentivos para cooperar con el presidente no se adapta al caso mexicano. La estructuración ideológica del sistema de partidos en México así lo demuestra. Son tres fuerzas políticas con una distancia moderada entre sí, un par de partidos (PRI y PAN) que comparten principios y valores programáticos e ideológicos, y los tres que tienden a desplazarse al centro del espectro político.

Coincidiendo con NOLTE (2003 p. 52), el bloqueo político que producen los gobiernos de mayorías divididas ha resultado en la práctica política menos complicado que en la teoría. Un mecanismo que prevalece para llegar a acuerdos entre los poderes ejecutivo y legislativo han sido los arreglos institucionales entre los actores en juego. En México, no se ha llegado a una disfunción institucional - 
léase ingobernabilidad - porque los partidos políticos, aún cuando ostentan ideologías diferenciadas, han logrado consensos para definir las políticas en el país.

Las relaciones entre los poderes ejecutivo y legislativo que han experimentado gobiernos de coalición son en gran medida una alternativa para evitar bloqueos y parálisis institucional. Chile es uno de los países que ha mostrado avance en esta ruta; Brasil también, aún con un sistema multipartidista polarizado, sus instituciones funcionan.

Lejos de descalificar los sistemas políticos con congresos de gobierno sin mayorías, es preciso reivindicar el pluralismo político en la arena parlamentaria. Si bien la fragmentación partidaria sigue siendo un obstáculo para construir coaliciones estables, los hechos muestran que las crisis de gobernabilidad provienen más de la cultura de corrupción que sigue enconada en la región latinoamericana, además del culto al personalismo y lealtades clientelares que se han convertido en la obstrucción de la calidad de la democracia. Dichos resabios del quehacer político de antaño pueden superarse mediante rediseños institucionales que regulen el comportamiento político de los actores en juego, instrumentando reformas que favorezcan la rendición de cuentas para un mejor aprovechamiento de los recursos y decisiones políticas.

Quizá sería oportuno poner a prueba la tesis sostenida por PÉREZ-LIÑÁN (2005), cuando afirma que, a corto plazo, el principal desafío para la gobernabilidad latinoamericana no está en el conflicto entre los poderes ejecutivo y legislativo, sino en la amenaza del alzamiento popular en un contexto de insatisfacción del funcionamiento de las nuevas democracias. Es decir, los esfuerzos tendrían que apuntar a valorar los alcances concretos que se han logrado en materia económica y social para garantizar mejores niveles de vida en la población. No puede ser incompatible democracia con calidad de vida, por el contrario, es este el reto que habría que tener presente en las agendas de gobierno. 
Referencias Bibliograficas:

ALCÁNTARA, M. Partidos políticos en América Latina: precisiones conceptuales, estado actual y retos futuros. Ponencia. En: Seminario Permanente Partidos Políticos y Sistemas Electorales. México: UAEMEX, IEEM, 2006.

ALCÁNTARA, M. y FREIDENBERG, F. Los partidos políticos en América Latina. Revista América Latina Hoy, Salamanca: Ediciones Salamanca, n² 27, p. 17-35, abr. 2001.

AMORIM NETO, O. Formação de gabinetes presidenciais no Brasil: coalizão versus cooptação. Nova Econômica, 4 (1), p. 9.34, 1994.

En defensa del semipresidencialismo, pero solamente para algunos países. EN: Seminario Internacional: Hacia el fortalecimiento de la gobernabilidad democrática: situación y perspectivas del presidencialismo y parlamentarismo en América Latina, 2004. Disponible en:

<http://www.upd.oas.org/lab/executive coo/events/2004/georgetown/merged ponencias.p df $>$. Consultado el 2 jun. 2006.

CAREY, J. Presidencialismo e instituciones representativas. En: DOMÍNGUEZ, J. y SHIFTER, M. (eds.). Construcción de gobernabilidad democrática en América Latina. Colombia: Fondo de Cultura Económica, 2005 (1996). . Límites a la reelección y representación legislativa. México: CIDE, 2006 (1996).

COLOMER, J. Reflexiones sobre la reforma política en México, 2003. Disponible en: $<$ http://www.grupochorlavi.org/php/doc/documentos/reflexionesmexico.pdf>. Consultado el 19 mar. 2007.

COLOMER, J. y NEGRETTO, G. Gobernanza con poderes divididos en América Latina. Revista Política y Gobierno, México: CIDE, vol. X, nº 1, p. 13-61, primer semestre 2003.

DOMINGUEZ, J. Construcción de gobernabilidad democrática en América Latina. México: FCE, Serie Continente Americano, 2005 (1996).

FERREIRA, R. y GORETTI, M. Estudio del Centro de Estudios de Políticas Públicas Aplicadas (CEPPA), 2006.

GODOY, A. Parlamento, presidencialismo y democracia protegida. Revista de Ciencia Política, Santiago de Chile, Vol. 23, $n^{\circ}$ 2, p.7-4, 2003. 
HANNAN, M. et al. A formal theory of Resource Partitioning, 2003. Disponible en: <http://faculty-gsb.stanford.edu/nagymaros/papers/files/partitioning may6.pdf>. Consultado el 12 abr. 2007.

JIMÉNEZ, M. La oposición parlamentaria en México: Su rendimiento en gobiernos de mayoría dividida. México: Miguel Ángel Porrúa y LIX Legislatura de la Cámara de Diputados, 2006.

LINZ, J. Democracia presidencial o parlamentaria: ¿qué diferencia implica? En: LINZ, J. y VALENZUELA, A. (Comps). La crisis del presidencialismo: Perspectivas comparativas. Madrid: Alianza Universidad, 1997.

LLAMAZARES, I. y SANDELL, R. Partidos políticos y dimensiones ideológicas en Argentina, Chile, México y Uruguay. Esbozo de un análisis espacial. Revista Polis, México: UAM-I, 00, nº extraordinario, p. 43-69, 2001.

LOVELAND, M. Religious swhitching: preference development, maintenance and change, 2001, Working Paper and Thecnical Report Series $n^{\circ} 6$, University of Notre Dame. Disponible en: <http://www.nd.edu/ soc2/workpap/2001/mll1.pdf>. Consultado el 28 feb. 2007.

MAINWARING, S. Presidencialismo, multipartidismo y democracia: la combinación difícil. Revista Sociología y Política, Nueva Época, México: Universidad Iberoamericana, $\mathrm{n}^{\circ} 7$, ano III, p. 115-144, 1995.

S. Presidencialismo y gobierno dividido. Foro: América Latina y México: saldo y oportunidades del gobierno dividido. Centro Latinoamericano de la Globalidad, May. 2004.

. S. y SCULLY T. La institucionalización de los sistemas de partido en la América Latina. Revista América Latina Hoy, Universidad de Salamanca, nº 16, p. 91-108, ag. 1997. (Comps). Presidencialismo y democracia en América Latina. Paidós: Buenos Aires, 2002 (1997).

McPHERSON, J. An ecology of afiliation. American Sociological Review, Vol. 48, p. 519.532, 1983.

NACIF, B. Policy making under divided government in Mexico. Working Paper $n^{\circ} 305$. México: CIDE, mar. 2003.

NOHLEN, D. Presidencialismo versus parlamentarismo: dos enfoques contrapuestos. En: NOHLEN D. y FERNÁNDEZ M. (Eds). El presidencialismo renovado: Instituciones y cambio político en América Latina. Venezuela: Nueva Sociedad, 1998. 
NOLTE, D. El congreso chileno y su aporte a la consolidación democrática en perspectiva comparada. Revista de Ciencia Política, Santiago de Chile, vol. XXIII, n² 2, 2003.

O’DONNELL, G. Pobreza y desigualdad en América Latina. Algunas reflexiones políticas. En: TOCKMAN, V. y O'DONELL, G. Pobreza y desigualdad en América Latina. Buenos Aires: Paidós, 1999.

PASQUINO, G. Oposición, gobierno sombra, alternativa. Por qué y cómo estudiar a la oposición. En: PASQUINO, G. La oposición en las democracias contemporáneas, $1^{\text {a }}$ ed. en español. Buenos Aires: Eudeba, 1997 (1990).

PÉREZ-LIÑÁN, A. Pugna de poderes y Crisis de Gobernabilidad: ¿Hacia un Nuevo presidencialismo?. Disponible en: <http://www.gobernabilidad.cl/modules.php?name=News\&file=article\&sid=972>. Consultado el 20 jul. 2006.

PRZEWORSKI, A. Democracia y mercado: Reformas políticas y económicas en la Europa del Este y América Latina. Cambridge: University Press, 1996.

SANI, G. y SARTORI, G. Polarización, fragmentación y competición en las democracias occidentales. En: SARTORI, G. Partidos y sistemas de partidos. Madrid: Alianza Editorial, 1999 (1980).

SARTORI, G. Partidos y sistemas de partidos. Madrid: Alianza Editorial, 1999 (1976).

SHEPSLE, K. y GONCHEK, M. Las formulas de la política: instituciones, racionalidad y comportamiento. México: Taurus, CIDE, 2005 (2004).

SHUGART, M. y CAREY J. Presidents and Assemblies: constitutional design and electoral dynamics. Nueva York: Cambridge, University, Press, 1992.

SHUGART, M. y MAINWARING, S. Presidencialismo y democracia en América Latina: revisión de los términos del debate. En: MAINWARING, S. et al. Presidencialismo y democracia en América Latina. Buenos Aires: Paidós, 2002 (1997).

SIAVELIS, P. Chile: las relaciones entre el poder ejecutivo y el poder legislativo después de Pinochet. En: LANZARO, J. (Comp.). Tipos de presidencialismo y coaliciones políticas en América Latina. Buenos Aires: CLACSO/ASDI, 2001. 
STEIN, E. et al (Coords). Progreso económico y social en América Latina. Informe 2006. Banco Interamericano de Desarrollo, David Rockefeller Center for Latin American Studies e Harvard University, 2006.

THIBAUT, B. El gobierno de la democracia presidencial: Argentina, Brasil, Chile y Uruguay en una perspectiva comparada. En: NOHLEN, D. y FERNÁNDEZ, M. El presidencialismo renovado: instituciones y cambio político en América Latina. Caracas: Nueva Sociedad, 1998.

TSEBELIS, G. Jugadores con veto: cómo funcionan las instituciones políticas. México: FCE, 2006 (2002).

ZOVATTO, D. y BURDMAN, J. Balance Electoral Latinoamericano 2003-2004. En: Observatorio Electoral Latinoamericano. Disponible en: <http://www.observatorioelectoral.org>, out. 2005. Consultado el 16 jun. 2005.

\section{OTRAS FUENTES DE CONSULTA:}

BASES DE DATOS DEL PROYECTO ELITES PARLAMENTARIAS EN AMÉRICA LATINA (PELA) 1994-2004. SÁEZ, M. A. (coord.). Instituto Interuniversitario de Estudios de Iberoamérica y Portugal, Universidad de Salamanca, [s.d].

BOLETÍN Ideología y valores de los parlamentarios latinoamericanos: Datos de opinión, Elites Parlamentarias Latinoamericanas. SÁEZ, M. A. (coord.). Instituto Interuniversitario de Estudios de Iberoamérica y Portugal. Universidad de Salamanca, [s. d.].

INFORME Latinobarómetro 2006. Disponible en: <http://www.latinobarometro.org/uploads/media/2006 02.pdf>. Consultado el 12 en. 2007. 